\title{
A THEORY OF HUMAN FLOURISHING FOR COMPANY DECISION-MAKING
}

\author{
By
}

Liina Bårdsen

\begin{abstract}
A thesis
submitted to the Victoria University of Wellington in fulfilment of the requirements for the degree of Master of Arts in Philosophy
\end{abstract}

Victoria University of Wellington 


\section{Table of contents}

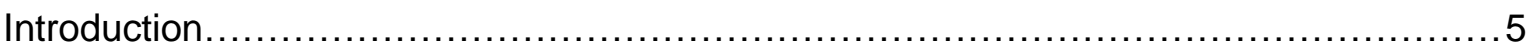

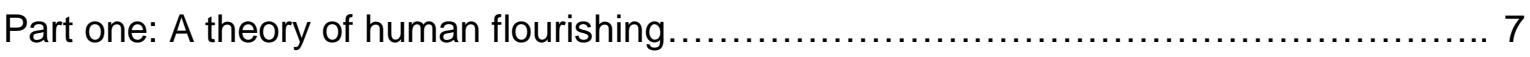

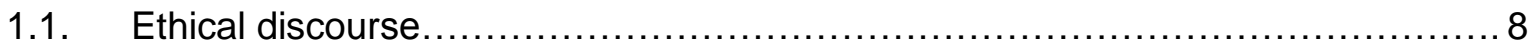

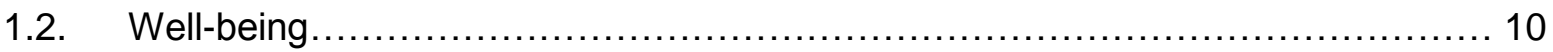

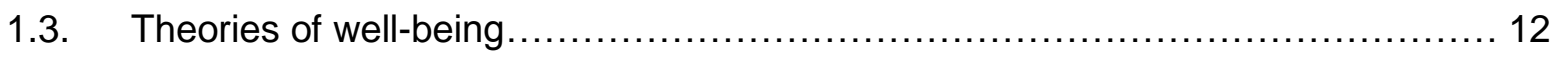

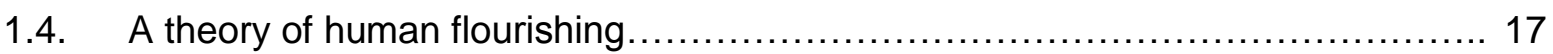

1.4.1. Naturalism and characteristic good human ends .............................. 20

1.4.2. The concept of meaning and characteristic good human ends ..................... 23

1.4.3. An objective account of well-being with room for subjective elements............... 26

1.4.4. Virtue ethics as a guideline for ethical deliberation.................................. 30

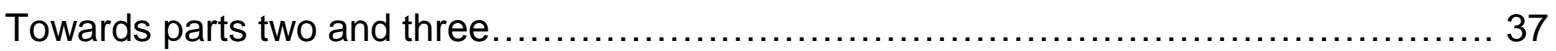

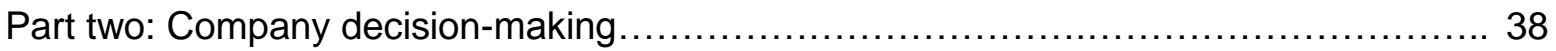

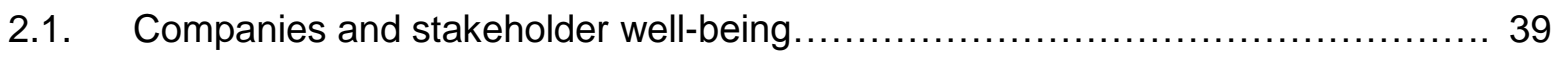

2.2. The shareholder theory of business ethics................................ 43

2.2.1. Primacy of shareholder interests versus equal concern for

2.2.2. Focus on economic benefits alone versus responsibility to practice

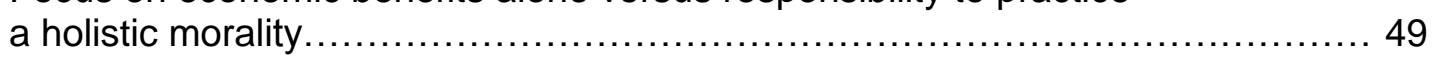

2.3. The stakeholder theory of business ethics....................................... 53

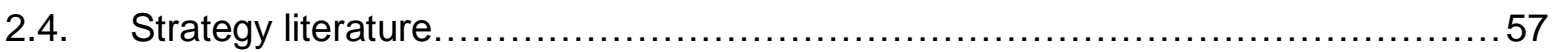

2.4.1. Formal, managerial decision-making versus stakeholder autonomy ...............6 60

2.4.2. Competitive approach to stakeholders versus search for shared meanings..........63

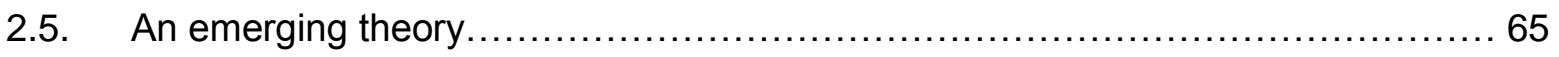

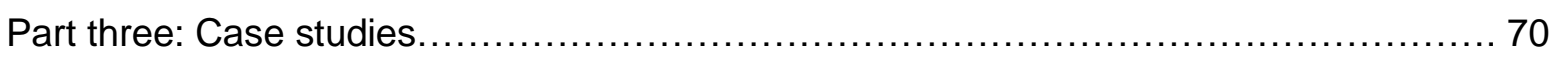

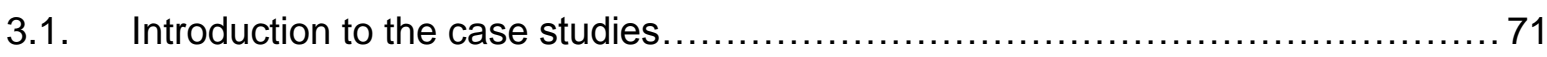

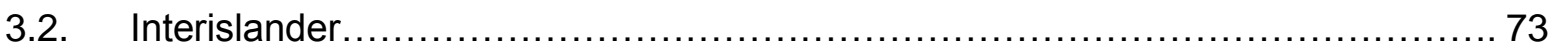

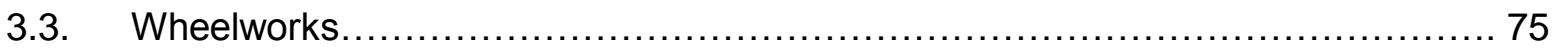

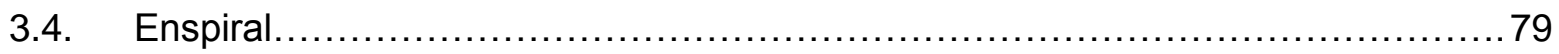

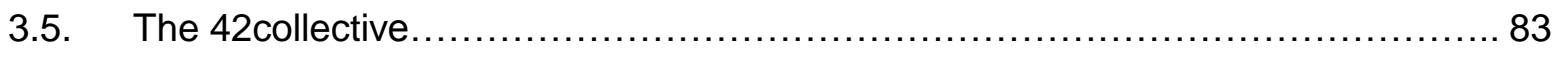




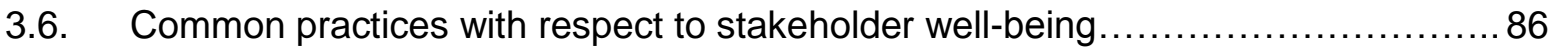

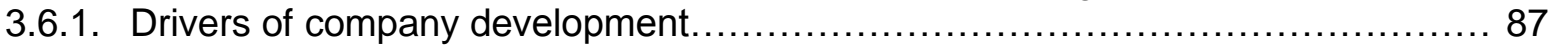

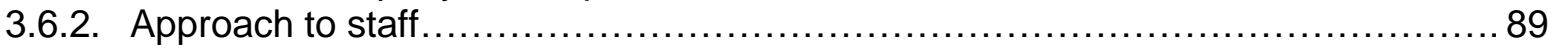

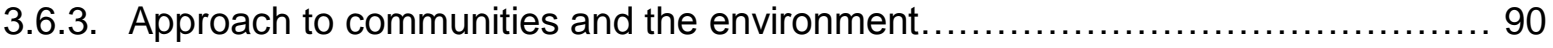

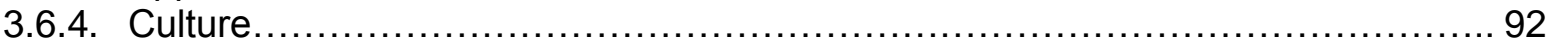

3.7. Emerging thoughts about the status of stakeholder well-being ....................94

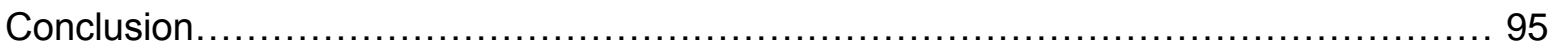

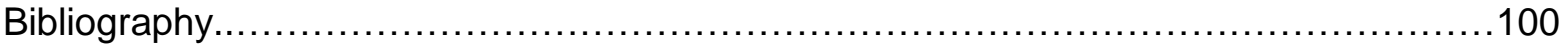




\section{Introduction}

Business is one engine of well-being, and the main engine of material well-being, in society. Companies produce goods and services that we would not be able to do without or that add comfort or pleasure to our lives, provide us with jobs, and help make our communities dynamic and lively. Still, businesses come increasingly under criticism for being the cause of many social, environmental and economic problems, and are often seen as prospering at the expense of individual people and the broader society. ${ }^{1}$ Also, as customers or employees of businesses, we are frequently dissatisfied with substandard product quality, unfriendly service, a work community in which not everyone is pulling in the same direction or leaders who do not inspire. We invest many resources and much energy and time in our roles that have to do with companies. In such a situation, it seems justified to ask whether businesses are fulfilling their potential, if viewed as agents of well-being.

My thesis aims to be one contribution to the active academic, political and societal debate we have in the Western world on the appropriate evolution of businesses in the 2010s. Faced with intensifying competition from developing world produce, large private and public sector debts restricting consumption opportunities at home, and social and environmental concerns about ways companies operate, Western businesses are re-thinking their strategies. Many progressive companies are going even further and are revising their objectives in ways that challenge our traditional conception of what a business is, what it does and how. ${ }^{2}$

\footnotetext{
${ }^{1}$ Michael E. Porter, one of the most prominent management theorists of the past three decades, writes about the lack of legitimacy in modern business in his most recent article, co-authored with Mark R. Kramer: Kramer, and Porter, "Creating Shared Value," Harvard Business Review, JanuaryFebruary 2011, 64. A similar argument is given by Dominic Barton, the managing director of one of the most influential management consultancies in the world, McKinsey \& Company: Barton, "Capitalism for the Long Term," Harvard Business Review, March 2011, 85.

${ }^{2}$ One interesting illustration of the type of changes we are currently seeing in the world of business is the growth of social enterprises. These are defined as businesses that are driven by a social or environmental purpose and that reinvest their profits to furthering such a purpose. In the UK, which is a leading country in the area, there are 62,000 social enterprises, contributing £24 billion to the national economy and employing 800,000 people: Social Enterprise Coalition, "About social enterprise," http://www.socialenterprise.org.uk/pages/about-social-enterprise.html (accessed April 15, 2011). One of my case study companies, Enspiral, is a social enterprise.
} 
In my thesis, I develop one ethical theory that could guide such evolution. A theory of human flourishing, I argue, puts businesses' stakeholders and their well-being at the centre of company operations. Consequently, company decision-making changes in important ways. I show that there are companies in the real world that operate according to a humanistic ethical theory, and do so successfully.

In part one of the thesis, I outline my theory of human flourishing. The theory is based on naturalistic virtue ethics. According to ethical naturalism, our lives go well for us if we live as it is characteristic for human beings to live. I identify five broad ends of a characteristic good human life, each deriving from our nature as rational, emotional, social and meaningseeking beings, yet as beings that also share many characteristics with other species.

I then ask, with the help of virtue ethics, how we can deliberate about which choice or action to favour in situations in which it is not immediately and intuitively clear to us what our and affected others' well-being requires. We can choose between different solutions by considering what reasons we have for proposing them, and what emotions they awaken in us. We are likely to do well to choose a solution for which we have good reasons and feel good about. Good reasons and emotions, in turn, are such that if we and other people had them and acted according to them, well-being would be enhanced in our individual lives and in our communities.

In part two, I compare and contrast my human flourishing conception of the good with conceptions presented in the business ethics and strategy literatures. This allows me to place my ethical theory in a framework familiar to companies and to tease out some important principles about the nature of business and company decision-making that my theory entails. I first argue that advancing human flourishing is not only our private concern but an appropriate task for companies, too. This view is contested both by the shareholder theory of business ethics and the strategy literature, both of which consider businesses' role to be maximisation of shareholder wealth.

According to my ethical theory, companies that take 'stakeholder well-being' - a term I use to describe human flourishing in the business context - seriously do not have such a 
singular focus. Instead, they consider, for each company decision, which stakeholders' interests are the relevant ones to prioritise and what these interests consist in, when the primary concern is with well-being. Furthermore, we can expect such companies to engage their stakeholders in decision-making and have an informal, collaborative attitude towards them. For humanistic companies, stakeholder well-being, rather than profit maximisation, is the proper objective of business and the motive for choosing one solution over another.

In part three, I look at four Wellington-based companies: Interislander, Wheelworks, Enspiral and Conscious Consumers. My interviews with three of these companies show that an orientation around stakeholder well-being is both possible and practical - and not contradictory with conventional business success. One of the interviews shows that companies that aim for profit maximisation also have good reasons to be interested in stakeholder well-being. Based on the case studies, I identify some practices with respect to stakeholder well-being that seem to be common to companies that cherish a humanistic ethical theory, independently of company or industry specifics. Of these, having a product or service that makes a genuine difference to customers' lives and going at great lengths to meet staff needs and wants appear as particularly important.

\section{Part one: A theory of human flourishing}

I will start part one with some comments about why it is not impossible that some moral views are better than others and why ethical discourse would make sense even if this were not the case. I will also say briefly why individual well-being seems to me to be an attractive concept on which to build an ethical theory. I will then move on to examine different theories of well-being and suggest that a compelling case can be made for a hybrid account that combines our subjective and objective intuitions about well-being. My main goal in this part is to develop a theory of human flourishing. The theory has two components: first, an account of what individual well-being consists in, and, second, guidelines for deliberation in 
situations in which we are uncertain about what individual well-being requires. My theory is based on naturalistic virtue ethics.

\subsection{Ethical discourse}

Our everyday ethical discourse assumes and implies certain positions in metaethics. Metaethics explores, among other things, the nature of moral properties, the status of moral statements and our knowledge of morality. ${ }^{3}$ Do moral properties, such as 'goodness', exist? If so, just what kinds of things are they? Are our moral statements, such as 'it is morally right for our company to pay for the environmental damage we cause', true? If so, what makes moral statements true? And what counts as sufficient justification for our moral beliefs?

Though such questions of metaethics are interesting, I will not explore them in this thesis, because I wish to avoid a commitment to a specific metaethical position that might limit my substantive argument. Before starting to develop my ethical theory, however, I need to gain acceptance for one assumption, if my project is to be interesting for all readers irrespective of their metaethical views: that ethical discourse makes sense.

We often disagree about moral questions. Moreover, we often find these disagreements difficult to resolve. ${ }^{4}$ Imagine a situation where the communications manager and the marketing manager of a company hold differing views about whether, in the absence of any legislation about the matter, their company ought to pay for the environmental damage it causes in the local community. The managers can find out whether it makes economic sense to pay for the pollution; they can compare past empirical evidence from other companies in similar situations, and they can reason about what would be likely consequences for their specific company if they chose one solution or another. Say that

\footnotetext{
${ }^{3}$ Geoff Sayre-McCord, "Metaethics," Stanford Encyclopaedia of Philosophy, http://plato.stanford.edu/entries/metaethics/ (accessed November 8, 2010).

${ }^{4}$ This is one type of argument the sceptic can put forward to question the possibility of moral knowledge or, more broadly, morality: Walter Sinnott-Amstrong, "Moral Skepticism," Stanford Encyclopaedia of Philosophy, http://plato.stanford.edu/entries/skepticism-moral// (accessed November 7, 2010).
} 
when they do such a calculus, they find out that the economic costs of paying for the environmental damage are very likely to be smaller than the economic benefits that accrue from a greater number of customers choosing their product as a result of an environmentally friendly company profile.

Still, the managers may continue to disagree about the company's moral obligation regarding the payment for pollution. They can, for example, adopt the position that the moral views they express are merely opinions or emotions instead of statements with a truth value, or that the truth value of their claims depends on their specific ethical outlooks and backgrounds instead of deriving from some universal standard. ${ }^{5}$ The communications manager can say that in his opinion, companies have moral obligations towards the communities in which they operate, one of which is not to affect these communities adversely. The marketing manager can contest this view, and say that in the ethical tradition she has adopted, moral obligations exist only between people and should not be mixed in with business thinking.

The managers' continued disagreement, however, does not mean that it would be impossible for one of the moral views put forward to be better than another, or that it would not make sense for the managers to discuss and debate the relative merits of their opposing moral views.

First, it might conceivably be the case that truth criteria for moral views exist, but we have just not yet been able to develop or discover them, especially in light of the domination of the methodology, requirements and world view of science in the modern era. Maybe moral truths are more like the axioms of mathematics or the laws of the arts - first principles justified by intuition instead of empirical evidence or logic. Or maybe moral truths are truths that share some common characteristics yet are available to us on a case-by-case basis,

\footnotetext{
${ }^{5}$ These two forms of anti-realism about morality are, respectively, non-cognitivism and relativism: Sayre-McCord, "Metaethics." Hilary Putnam suggests that the prevalence of these two forms of antirealism in ethics is a consequence of the broader dominance of logical positivism in $20^{\text {th }}$ century philosophy: Putnam, "Objectivity and the Science-Ethics Distinction, " in The Quality of Life, ed. Martha C. Nussbaum, and Amartya Sen (New York: Oxford University Press, 1993), 143-145.
} 
through a holistic assessment of what is good or right or virtuous for given individuals in given circumstances, based on all the knowledge we have of human beings.

Second, even if absolute truth criteria for moral views were never to be developed or discovered, we may still be able to distinguish between better and worse moral views in any given situation by assessing the situation with some standards that the parties involved and affected by the situation find commonly acceptable. In the above case, the marketing and communications managers may, for example, be able to come to an agreement that paying for the environmental damage the company causes looks like a better moral view, because it allows the company decision-makers to keep their integrity, or because fewer people will benefit from higher company profits and more people will benefit from clean air.

Third, even if truth criteria for moral views were never to be developed or discovered, we may do well to keep open the possibility that some moral views have more merit than others and to engage in a dialogue about what exactly the greater merit could consist in. This is because the mere process of questioning our views and being informed by others' views has value of its own. The process may, for example, lead us to hold internally more consistent moral views and thereby be more mature or happier individuals, or it may allow us to converge around certain commonly held ethical standards as communities and societies.

Fourth, it may just be a human predicament to keep on searching for truth criteria for our moral views. Here, the thought is that even if such a search did not bring us any value, and could even be disadvantageous to us, we cannot avoid it, being the rational and sentient beings we are.

If the communications and marketing managers accept one or more of the above arguments, they have a reason to continue their ethical discourse, even if they are unable to agree on truth criteria for moral views.

\subsection{Well-being}


An ethical theory can be built on any one of a number of basic concepts. To give just a few examples, we can be interested in what is good, right, our own or someone else's duty or right, or virtuous. ${ }^{6}$ Just as I do not take it as my task in this work to establish a firm metaethical position, I do not aim to determine which of these concepts is the most attractive one for ethical discourse and why - this question has been the occupation of many philosophers' life work. I choose to develop my argument as an argument about the good, because it looks like a case can be made for understanding other basic concepts in ethics in terms of the good. If we ask why something is right, or our duty, or virtuous, it seems to be one credible answer to say: 'because it is what is good.'

The good, however, is a very broad concept. In this thesis, I will focus on the human good, and consider other species' good only insofar as it is a part of our own good. This does not mean that I think we should not care about other species' good. Certainly, I believe that we should care about animals' good, because they, too, are sentient beings. Further, I believe that our unique ability to care about other species' good for its own sake places a special responsibility on us to do so. I will just not address other species' good in this work. Neither will I consider inanimate entities', such as companies', good, if such exists. ${ }^{7}$

As for the human good, I will acknowledge both its solitary and sociable ingredients. Given my intention to apply the ethical theory I develop to a business setting, the sociable elements are likely to receive more attention in my treatment of the good. Our good depends greatly on other people: the interactions and relationships we have in our communities. Again, however, I do not consider communities' good to be anything other than, or separate from, the goods of their individual members.

\footnotetext{
${ }^{6}$ Leonard W. Sumner lists a number of foundationalist ethical concepts around which ethical debate can be organised: axiological (good and bad), practical (ought and should), deontological (duties, rights, justice) and aretaic (virtues and vices). Sumner, Welfare, Happiness, and Ethics (New York: Oxford University Press, 1996), 185.

${ }^{7}$ There is debate among business ethicists about whether companies are moral agents or not: Alexei Marcoux, "Business Ethics," Stanford Encyclopedia of Philosophy http://plato.stanford.edu/entries/ethics-business/ (accessed January 28, 2011). If companies are treated as moral agents, it is conceivable that we could also ask a question about what is a company's 'good'.
} 
I understand the human good as individual well-being, or what makes our lives go well for us. ${ }^{8}$ There are other ways of understanding the human good, such as what is good for us (irrespective of what we ourselves think of it), or what is good according to us (our opinion, irrespective of whether it advances our well-being or not). ${ }^{9}$ I give preference to the definition of human good as individual well-being for two reasons.

First, I believe that a good theory of well-being needs to allow for an intimate connection between our own views about the good and what is in fact our good. It seems to me highly implausible that things can genuinely make our lives go well for us, if we ourselves don't believe, think or feel that they do. Second, I believe that a good theory of well-being also needs to acknowledge the possibility that we can sometimes be mistaken about our well-being. It seems to me plausible that not all things necessarily make our lives go well for us, even if we ourselves believe, think or feel that they do. I will now look at the proposition that a good account of well-being incorporates both a subjective and an objective element in more detail.

\subsection{Theories of well-being}

The concepts 'subjective' and 'objective' are commonly used in the development of theories of well-being, but are understood differently by different authors. ${ }^{10}$ As my project is to develop an understanding of well-being that can be applied in situations of ethical decision-making, I take subjective theories of well-being to be theories on which individuals themselves are the sole authorities in deciding whether and how various choices and actions open to them enhance (or reduce) their well-being. Objective theories of well-being, in turn, are to me theories on which the well-being enhancing (or reducing) potential of ethical decisions is assessed against some external standard of goodness.

\footnotetext{
${ }^{8}$ Thomas Scanlon, "Value, Desire, and Quality of Life," in The Quality of Life, ed. Martha C. Nussbaum, and Amartya Sen (New York: Oxford University Press, 1993), 185.

${ }^{9}$ Simon Keller, "Welfare as Success," Nous 43, no. 4 (2009): 656.

${ }^{10}$ Ibid., 660.
} 
To illustrate this distinction, assume that the human resource manager of a company is faced with a decision whether to give one of her key employees significant time off in a period critical to the company's new product launch because the employee's ageing mother is ill. Under a subjective account, if the employee is of the view that time off would enhance his well-being then so it does. The employee's attitude gives the manager a reason to give him time off. Under an objective account, the manager may conclude - for example by referring to what we know about the need of people to be with their loved ones when illness strikes - that time off enhances the employee's well-being, even if the employee sincerely insists that it does not matter to him whether he spends time with his mother. Here, the reason for the manager to give the employee time off is external to the employee's attitude. ${ }^{11}$

Theories of well-being are commonly categorised into subjective mental state theories and desire theories on one hand and objective substantive good theories on the other. $^{12}$

Starting from subjective theories, mental state theories maintain that our experiences determine our well-being; our life is going well for us if we have certain subjective experiences. Desire theories, in turn, say that our preferences determine our well-being; our lives are going well for us to the degree that we get what we want in life. The two accounts fit rather well with a distinction drawn in modern psychological research between the experiencing self and the reflective self, where the former evaluates our present state of wellbeing and the latter how well we are doing in our lives overall. ${ }^{13}$ Both mental state and desire

\footnotetext{
${ }^{11}$ This definition of the subjective-objective distinction is close to the definitions given by Sumner, Welfare, Happiness, and Ethics, 35 and Keller, "Welfare as Success", 660.

${ }^{12}$ Scanlon, "Value, Desire, and Quality of Life", 186-188. Roughly the same categorisation is used by Sumner, Welfare, Happiness, and Ethics, 35, Keller, "Welfare as Success", 657-660, and Valerie Tiberius: Tiberius, "Well-Being: Psychological Research for Philosophers," Philosophy Compass 1, no. 5 (2006): 494-498. The discussion of the following paragraphs draws on these accounts of the three categories of theories of well-being. A recent excellent review of theories of well-being is provided in Marie J. C. Forgeard, Eranda Jayawickreme, Margaret L. Kern, and Martin E. P. Seligman, "Doing the Right Thing. Measuring Wellbeing for Public Policy," International Journal of Wellbeing 1, no. 1 (2011): 79-106. http://www.internationaljournalofwellbeing.org/index.php/ijow/article/view/4 (accessed March 16, 2011).

${ }^{13}$ Daniel Kahnemann, "The Riddle of Experience vs. Memory," TED, http://www.ted.com/talks/daniel kahneman the riddle of experience vs memory.html (accessed January 7,2011$)$.
} 
theories fit our intuition that in situations of ethical decision-making, our own assessment of our well-being is what matters. However, the theories also face serious objections.

Mental state theories suffer from the shortcoming that they allow individuals to have positive experiences that are detached from reality. The employee with the ill mother may, for example, choose to ask for time off - and the human resource manager may decide to grant him leave - because to him, being by his mother's beside is a peaceful experience of fine mother-son bonding. It may be the case, however, that the mother would much prefer her daughter rather than her son to take time off work, as she finds her son's company distressing. Here, the employee's conception of his well-being is based on a mistaken understanding of the world, and a life based on falsehoods, assuming that there are other significant matters about which the employee is mistaken, cannot be a life that goes well for him.

Desire theories, in turn, face the criticism that they allow individuals to make choices and engage in activities that either have nothing to do with their well-being or are directly contrary to it. The employee may, for example, develop a preference for never leaving his mother alone again, insisting on staying by her bedside 24 hours a day and losing his job and own family in the process. Here, he has for some reason developed a perverse preference, and his well-being is certainly not advanced by his decision to ask time off - or by the manager's decision to give him leave. Desire theories also face the additional complication, for which there is ample evidence in psychological research, that we as human beings make inaccurate predictions about what will be well-being-enhancing for us in the future and misremember the degree to which various past experiences advanced our wellbeing. This leads us to have preferences that, if they materialise, do not always make our lives go better for us. ${ }^{14}$

A common strategy for subjective theories of well-being in responding to the above problems of misinformed experiences, odd preferences and cases in which the self is split in

${ }^{14}$ Tiberius, "Well-Being: Psychological Research for Philosophers," 495-496. 
two is to introduce some idealised conditions which we expect to apply to individuals when they make ethical decisions.

Mental state theories, for example, may admit that people's experiences are a reliable guide to their well-being only if they are truth-adjusted to the actual state of affairs in the world and are harmonious with the reflective self's assessment of one's values and goals in life. ${ }^{15}$ Desire theories, similarly, may allow well-being assessments to be informed only by preferences that people would have if they appreciated the true nature of what they desire in light of how the world works for them and for others and what their experiencing self would actually appreciate if these preferences came to be realised. ${ }^{16}$ The shared acknowledgement in these responses is that what individuals happen to want is not the whole story of their wellbeing ${ }^{17}$ - some sorts of objective conditions, if not assessment against an external standard of goodness, are required for individuals to be able to always choose and act so that their well-being is enhanced.

Objective theories of well-being take a further step and suggest that our choices and actions be guided by an assessment against an external standard of goodness. Substantive good theories propose that this external standard should be the degree to which our choices and actions allow us to achieve goods that make our lives go better for us. There are many variants of substantive good theories depending on how 'goods' are specified; some understand well-being to consist in our human rights being respected, others consider wellbeing to be advanced if our basic needs are met or if we attain capabilities that allow us to achieve valuable functionings, while yet others make well-being depend on adopting given behaviours in given situations. ${ }^{18}$

\footnotetext{
${ }^{15}$ These adjustments are discussed, respectively, by Tiberius, "Well-Being: Psychological Research for Philosophers", 497, and Sumner, Welfare, Happiness, and Ethics, 167-171.

${ }^{16}$ These adjustments are discussed, respectively, by Scanlon "Value, Desire, and Quality of Life," 187, and Kahnemann, "The Riddle of Experience vs. Memory."

${ }_{17}^{17}$ Keller, Welfare as Success," 658-659.

${ }^{18}$ One prominent proponent of the basic needs theory is John Rawls, as explained by Gerald A. Cohen: Cohen, "Equality of What? On Welfare, Goods and Capabilities," in The Quality of Life, ed. Martha C. Nussbaum, and Amartya Sen (New York: Oxford University Press, 1993), 9. The capabilities approach has been advocated among others by Amartya Sen: Sen, "Capability and Wellbeing," in The Quality of Life, ed. Martha C. Nussbaum, and Amartya Sen (New York: Oxford University Press, 1993), 36. Both of these are described as needs-based accounts of well-being by
} 
The strength of all variants of substantive good theories is that they establish a criterion of well-being against which we can assess individuals' ethical decisions when we are in doubt about whether these decisions indeed make lives go better for the people concerned. The theories fit our intuition that in situations of ethical decision-making, some choices and actions just are better than others, and that their relative goodness is not always or solely decided by how the involved individuals assess the situation. However, as with subjective theories, objective theories of well-being face a serious criticism.

To be able to guide us in practical ethical decision-making, substantive good theories have to elaborate on what they understand substantive goods to be. Various lists of goods have been put forward. Escaping morbidity and mortality, being adequately nourished and having the ability to achieve complex functionings, such as being happy, achieving selfrespect and taking part in the life of community, is one example of an objective list. ${ }^{19}$ Appropriate behaviours with respect to early infant development, mortality, the body, pleasure and pain, cognitive capability, practical reason, affiliation and humour is another example of such a list. ${ }^{20}$

But we may ask whether any such list, no matter how carefully put together, can fit the great variety of situations in which people choose and act. Maybe the list proposed lacks some elements of well-being that are essential, or maybe it is too comprehensive so that not all goods on the list make all individuals better off, or maybe different situations require, or different individuals prefer, different interpretation or prioritisation of the goods. ${ }^{21}$ The human resource manager may, for example, consider flexibility of employment according to people's life cycle a good conducive to employees' well-being, but say that fulfilling significant work commitments has an even greater well-being effect for them. The employee seeking leave to

Forgeard et al., "Doing the Right Thing. Measuring Wellbeing for Public Policy," 88-89. The behaviours approach is the agenda of virtue theorists to whom I will return soon in much more detail. ${ }_{10}^{10}$ Sen, "Capability and Well-being," 36.

${ }^{20}$ Martha C. Nussbaum, "Non-Relative Virtues: An Aristotelian Approach," in The Quality of Life, ed. Martha C. Nussbaum, and Amartya Sen (New York: Oxford University Press, 1993), 265.

${ }^{21}$ Keller, "Welfare as Success", 659. 
spend time with his ill mother has a different understanding of the order of these goods, and therefore thinks he is made worse off by the manager's decision not to give him leave.

Various objective theories of well-being respond to the difficulty of defining a list of goods that would fit all situations and decision-makers by allowing for some form of contextsensitivity or personalisation. The basic need theories, for example, introduce the idea that different people will have different needs in different situations depending on their interests, concerns or aims. ${ }^{22}$ The capability theories, in turn, allow for personal valuations that will determine which functionings are most valuable for any given individual; freedom to choose among alternative sets of functionings and the integrity that comes from this choice are considered important ingredients of well-being. ${ }^{23}$ The behaviour theories, which are influential for my account of human flourishing, appeal to the use of reasoning and emotions that lead to different choices and actions in different situations.

The above discussion suggests that subjective theories of well-being are enhanced if they subject individuals' own experiences or preferences to an external check, while objective theories of well-being do better if their assessment of the well-being potential of choices and actions gives a special weight to individual's own experiences and preferences. Maybe then it is not possible to hold on to either a purely subjective or a purely objective account of well-being, but necessary to acknowledge that a credible theory of the kinds of things that make us better off must be sensitive to our similarities as well as our differences, and the similarities and differences in our circumstances. I will now move on to propose one such hybrid account of well-being, the central notion within which is a particular understanding of human flourishing.

\subsection{A theory of human flourishing}

\footnotetext{
22 Sumner, Welfare, Happiness, and Ethics, 59.

${ }^{23}$ Sen, "Capability and Well-being," 35-39.
} 
The theory of human flourishing I have in sight is rooted in ancient virtue ethics - in Aristotle's writings, in particular. Ancient virtue ethics has been revived in the past few decades through the work of modern virtue theorists. The writings of Rosalind Hursthouse and Philippa Foot, pioneers of a contemporary version of Aristotelian, naturalistic virtue ethics, are most influential for my theory of human flourishing. ${ }^{24}$ This theory has two components.

First, I develop a naturalistic account of well-being. In a broad sense, ethical naturalism is a metaethical position on which ethical claims - and these can be claims specified in terms of the good, the right or any other basic ethical concept - are grounded in facts about human nature. ${ }^{25}$ For the purposes of this thesis, I understand ethical naturalism more narrowly as a theory of well-being that asserts that what makes our lives go well for us is living as it is characteristic for human beings to live. ${ }^{26}$ In my particular variant of the account, individual well-being is contingent on living as the rational, emotional, sociable and meaning-seeking species we are, acknowledging our similarities with other species.

In some situations of ethical choice and action, a naturalistic account of well-being may be all we need; seeing the alternative solutions, it is immediately and intuitively clear to us which of them individual well-being recommends. In many situations of ethical choice and action, however, we are likely to be unsure about how the goodness of the different solutions compares. This is certainly true in the business setting, given the large number of people whose well-being is affected by companies' decisions. Thus, we need to go beyond a naturalistic account of well-being to an ethical theory that is capable of guiding our actions and choices. ${ }^{27}$

\footnotetext{
${ }^{24}$ I have studied the following modern virtue theorists: Philippa Foot, Natural Goodness (New York: Oxford University Press, 2001), Rosalind Hursthouse, On Virtue Ethics (New York: Oxford University Press, 1999), Julia Annas, The Morality of Happiness (New York: Oxford University Press, 1993), and Martha Nussbaum, "Non-Relative Virtues: An Aristotelian Approach." Also Sumner has a good discussion of virtue ethics in Welfare, Happiness, and Ethics.

${ }^{25}$ Annas, The Morality of Happiness, 136.

${ }^{26}$ Foot, Natural Goodness, 14.

${ }^{27}$ Ibid., 9.
} 
Here, I turn to virtue ethics - the second component of my theory of human flourishing. In a broad sense, virtue ethics claims that ethical decision-making or deliberation is about choosing and acting as the virtuous person would. ${ }^{28}$ This involves showing appropriate virtues, in appropriate ways and for appropriate reasons. ${ }^{29}$ In this thesis, I argue for a narrower interpretation of virtue ethics as a guideline for how to weigh our reasons and emotions in situations of ethical choice and action. We are likely to do well to choose solutions for which we have good reasons and feel good about. Good reasons and emotions, in turn, are such that if we and other people had them and acted according to them, wellbeing would be enhanced in our individual lives and in our communities.

Putting the two components of my theory together, if we follow a naturalistic account of well-being and live as it is characteristic for human beings to live, and if we follow virtue ethics and deliberate well in situations of ethical choice and action, we achieve human flourishing.

A naturalistic virtue ethics theory of human flourishing is attractive to me for three reasons. First, as we have seen above, theories of well-being seem to be at their most credible when they incorporate both a subjective and an objective element. A theory of human flourishing does this, as its concern is my well-being, and as my well-being is determined by the extent to which I, through use of characteristic human rationality and emotions, achieve characteristic human ends. ${ }^{30}$ Second, a theory of human flourishing accommodates many different aspects of well-being: cognitive and affective, individual and collective, short term and long term. It also gives us an open-ended process for ethical deliberation about choices and actions rather than a fixed set of principles for ethical decision-making. Both of these characteristics make the theory well-suited for my purpose of bringing ethics to bear on business realities. Third, the concept of human flourishing seems to me to capture many valuable ideas about well-being that we give little weight to in our time

\footnotetext{
${ }^{28}$ Hursthouse, On Virtue Ethics, 1, and Annas, The Morality of Happiness, 27-28.

${ }^{29}$ Hursthouse, On Virtue Ethics, 11.

30 I base this definition of human flourishing on the following passages: Foot, Natural Goodness, 2944, Hursthouse, On Virtue Ethics, 195-210, and Sumner, Welfare, Happiness, and Ethics, 69-79.
} 
and culture, both generally and in business contexts. In this respect, it is a fruitful concept for a project like mine.

\subsubsection{Naturalism and characteristic good human ends}

A naturalistic account of well-being asks how it is characteristic for human beings to live. A comparison between us and other species provides a helpful starting point for thinking about the characteristics of our own species, which we then can modify to reflect the unique features of human life. ${ }^{31}$ The project uses all the knowledge we have from disciplines that study life in general and human beings and human behaviour in particular: biology, neuroscience, psychology, sociology, history, philosophy and so forth.

In this thesis, I follow Foot's and Hursthouse's accounts of a characteristic human life, formulating my own variant of them that describes the features of human life in general but is also well-suited for discussions in the business context, based on my experiences of this context. As I do not review the evidence for their or my account of a characteristic human life, I do not claim that it is superior to some potential rivals. What I aim for is a description of a characteristic human life that is accurate enough to get meaningful conversations about well-being started in companies. ${ }^{32}$

First, a characteristic life, from the naturalistic viewpoint, can be described in terms of the ends that that life has. On this view, when we ask whether a particular individual is living a life that is characteristic of the species, we are effectively asking whether the ends of that individual's life are characteristic of the species and whether she achieves those ends. ${ }^{33}$ This seems plausible. All things plants and animals do are done for a purpose. Though some

\footnotetext{
${ }^{31}$ Foot is particularly well-known for being a modern pioneer for this approach: Natural Goodness, 2645. Hursthouse also follows it: On Virtue Ethics, 195-235.

${ }^{32}$ I tested my description of a characteristic human life with some 15 post-graduate students at the School of Philosophy at Victoria University, when presenting my thesis. They all raised their hand affirmatively to the following question: "Do you believe this is an accurate description of the types of things that tend to make people well-off?" Also, I tested my description with the companies I interviewed for the final part of the thesis. Their managers, too, seemed to agree with it. These samples are of course very small and not representative, but interesting nonetheless.

${ }^{33}$ Annas, The Morality of Happiness, 30, Hursthouse, On Virtue Ethics, 198-201, and Foot, Natural Goodness, 31-35, all develop their accounts of naturalistic virtue ethics in this way.
} 
things that we humans do have no purpose - for example, touching one's hair or staring into the distance when writing - whenever we decide to choose or act, we do so in order to achieve some goal (of which we may be more or less conscious). Indeed, when we assess our choices and actions, a key part of our assessment is to ask ourselves why we choose or act as we do. The answer is given in terms of the ends that our choices or actions have.

Second, characteristic ends, from the naturalistic viewpoint, are also what are or appear to be good ends for the species. For plants and animals, characteristic ends are by definition good ends; if we conclude that some ends are characteristic for a plant or animal species, we are saying that attainment of those ends is what distinguishes a good specimen of that species from a poor specimen. For our own species, matters are more complicated, because we have the ability to freely choose between various ends. Still, we choose ends that appear to us to be good ends. ${ }^{34}$ This, too, seems plausible. We may choose ends that clearly are not good, but we choose these ends because we assess them to be good, from some perspective, in some way, somewhere along the line. The freedom unique to our species opens up the possibility that we may choose poor ends, but then we choose them because we mistake them for good ends - they are what appear to us to be good ends. ${ }^{35}$

Even if we do not always choose good ends, a naturalistic account of well-being maintains that such ends exist for human beings, just as they exist for plants and animals. For plants, characteristic good ends are quite simple: self-maintenance and reproduction. ${ }^{36}$ For animals, we add pleasure and freedom from pain, as well as good functioning of a social group, exemplified by bees dancing when they discover food or monkeys scratching each other's backs. ${ }^{37}$

How about human beings? Is there a discontinuity between other species and us? If we take ourselves to be part of the order of living things in the world, as we do in naturalism,

\footnotetext{
${ }^{34}$ Annas, The Morality of Happiness, 30-31.

${ }^{35}$ Maybe it is possible for us to choose ends because they are bad, but this is very unusual, at best.

${ }^{36}$ Foot, Natural Goodness, 31-34.

37 Hursthouse, On Virtue Ethics, 199-201.
} 
there should not be. ${ }^{38}$ Based on our knowledge of human beings and human behaviour, we seem to share the same characteristic good ends that other species of the natural world have: self-maintenance, reproduction, achievement of pleasure and freedom from pain, and good functioning of a social group. ${ }^{39}$

But surely there are some ends that are uniquely human; we are, after all, the only species capable of intelligent perception, reasoning and - as a result - free choice, as discussed above. Moreover, our sociability is more advanced compared to other species due to our capacities for language. Often, manifestations of our rationality, such as planning and managing our lives and asking and answering questions about how we ought to live, and manifestations of our more advanced sociability, such as affiliation and humour, are added onto the list of characteristic good ends for human beings. ${ }^{40} \mathrm{I}$ choose to treat our rationality, our emotions that can be rationally approached and are therefore a more complex matter for us than for other species and our sociability as capabilities rather than as a source of distinct ends.

Our rationality, emotions and sociability allow us, firstly, to choose how to 'live true' the ends that we share with animals and plants in characteristically human ways and in ways that respect our individual capabilities, likes and life projects. Secondly, our rationality and emotions allow us to assess whether and to what extent we are managing to do so. On this understanding, we do not have separate goals that derive from our rationality, emotions and sociability but instead, our abilities to reason, feel and connect with each other in advanced ways are essential parts of how we pursue all of our ends and why we choose as we do.

This seems to me a more accurate way of characterising the unique freedom of choice that our species have. Once more, this freedom includes the possibility that sometimes we choose poorly, but if our reasons and emotional responses are well-tuned

\footnotetext{
38 Ibid., 206.

39 lbid., 209. An excellent description of how the characteristic human ends, which we understand increasingly well due to recent developments in human sciences, and especially in neuroscience and experimental psychology, play out is provided by David Brooks: Brooks, "Social animal: how the new sciences of human nature can help make sense of a life," The New Yorker, January 17, 2011.

${ }^{40}$ Nussbaum, "Non-Relative Virtues: An Aristotelian Approach," 265.
} 
towards human flourishing - a point I will treat at length below when discussing virtue ethics as a guideline for ethical deliberation - we are likely to make good choices. The freedom to choose both ways and autonomously, in an increasing degree when we grow from childhood to adulthood, is important for individual moral progress; for learning the characteristically human ways to behave.

I then suggest the following initial list of good ends for a characteristic human life, attempting to formulate the ends we share with other species in a way that acknowledges our rationality, emotions and sociability and that makes sense also in a business context:

- Good health (compare with self-maintenance for other species);

- Bringing up the next generations so that they gain good preconditions for their wellbeing and caring for the previous generations so that they get the respect they deserve (compare with reproduction);

- Enjoying our existence (compare with pleasure and freedom from pain);

- Pursuing projects that sustain and develop a community (compare with good functioning of a social group);

- Living as part of our natural environment and so that the resource constraints of our planet are respected (a new end arguably required for long-term sustenance of our species, given the knowledge we have of the impact of our current behaviours on the viability of the planet).

\subsubsection{The concept of meaning and characteristic good human ends}

The above account is one suggestion of what individual well-being consists in: how things are when our lives are going well for us. Still, it does not seem to me to capture the full sense of what it is like to be a person who is well-off: to sense that our lives are going well for us. To gain a better understanding of this, I go a little outside of naturalism, for a moment. 
What follows, however, is outside naturalism only in that the claims are not often treated by naturalist theorists. I believe that they are equally descriptive of living as the species we are as are the above considerations.

Several philosopher-psychologists, whom we might loosely call philosophers of meaning, suggest that what is most essential about being a human being is a unique search for meaning in our choices and actions, and in our lives overall. ${ }^{41}$ Without going into too much detail, our search for meaning has the following attributes.

First, the source of meaning is most often outside of ourselves, in the interactions we have with our fellow human beings and the world. ${ }^{42}$ Second, we find meaning mainly in experiences, most powerfully in the experience of love (or any other positive human-human or human-world experience, such as the experience of truth, beauty or goodness). However, we also find meaning in accomplishments - or what I described as projects on the initial list of human ends - such as creating something of value or accomplishing a worthwhile task, and in coming to terms with the inevitable suffering that belongs to human life. ${ }^{43}$ Third, intuition, in addition to other feelings and reasoning, has a special role in guiding us towards meaning, and we know that we have found it when we have an easily recognisable, undeniable, heart-felt sensation of meaningfulness. ${ }^{44}$ Finally, the potential for meaning is present in and unique for every encounter we have with each other and with the world. ${ }^{45}$

To illustrate the importance of meaning for our well-being, consider an employee working in the product development unit of a company. After toiling long and hard on a particularly complex feature of the product essential to lengthening its life cycle, she finally cracks the code of how the product should be manufactured for greater endurance. She takes great joy in this individual achievement, thinking back to all the problems she has

\footnotetext{
${ }^{41}$ Central philosophers-psychologists in this group are Max Scheler, Victor Frankl and Abraham Maslow. My characterisation of their philosophy is based on discussions with my father Risto Luukkonen and his quote based notes on some of Scheler and Frankl's key works and secondary literature by Ulla Solasaari and Ann V. Graber.

${ }^{42}$ Ibid, notes on Frankl.

${ }^{43} \mathrm{Ibid}$, notes on Graber.

${ }^{44} \mathrm{Ibid}$, notes on Solasaari.

${ }^{45}$ Ibid, notes on Frankl.
} 
solved along the way and the good things that ensue from the result. Precious raw materials are going to be saved and customers can have a well-functioning, beautiful product for much longer than they used to. When having such feelings and thoughts, the employee is sensing that her work is meaningful. There seems to be something more going on here than merely her enjoying her work and pursuing a valuable project.

Moreover, her achievement connects to the overall aspiration of the company she works for to be a leading supplier of durable, aesthetic and environmentally friendly products. When she shares the results of her work with her manager and colleagues, they get enthusiastic and start planning how her innovation is going to play out in the manufacturing process. Things can be done in unforeseen ways. Working through the process improvements - and maybe in particular when they go out for a beer to celebrate the launch of a new production line - the employees of the company share a sense of meaningfulness; life here and now is good. Again, there seems to be something more going on here than simply the employees enjoying their work and pursuing a valuable project.

The above insights from philosophers of meaning seem to fit well with and complement the insights of a naturalistic account of well-being. First, the idea that a search for meaning characterises our lives as a whole, and that a sensation of meaningfulness describes moments when we feel most fully alive, is not foreign to an ethical theory which also emphasises the unified nature of good human choices and actions. ${ }^{46}$ Second, our search for meaning, though externally oriented, manifests itself in internally sensed states. Consequently, its achievement is not externally observable in the same way as the achievement of the more concrete ends we share with other species, such as good health or pursuing projects that sustain and develop a community, is. Still, an argument can be made that our search for meaning is equally naturalistic, if the internal states can be sensed by all of us, in virtue of our humanity. Evidence for this is compelling. ${ }^{47}$ Third, the proposition that a

\footnotetext{
${ }^{46}$ Foot, Natural Goodness, 5.

47 Mihaly Csikszentmihalyi's concept of 'flow states' comes close to what I understand by an internally sensed state of meaningfulness. His extensive research on flow states with different kinds of people in various cultures seems to suggest a similar universality to experiences of flow as we find for our
} 
sensation of meaningfulness accompanies achievement of our ends - that we can say something qualitative about how it is to live in characteristically human ways - seems genuinely additional to what we have said before.

To incorporate the key ideas from philosophers of meaning into my account of wellbeing, I choose to describe two of the characteristic good human ends suggested above with the adjectives 'meaningful' and 'often shared'. Through the description 'often shared', I hope to acknowledge that some of our enjoyments, creations and tasks are solitary but most are sociable, due to the nature of our species. Through the description 'meaningful' (instead of inclusion of the pursuit of meaning as a separate end), I wish to emphasise the thought that we are more likely to achieve meaning in our lives if we aim for concrete things that we sense as meaningful, instead of aiming for something as conceptually abstract as 'meaning'.

I then suggest the following modified list of good ends for a characteristic human life:

- Good health;

- Bringing up the next generations so that they gain good preconditions for their wellbeing and caring for the previous generations so that they get the respect they deserve;

- Meaningful, often shared enjoyment of our existence;

- Meaningful, often shared projects that sustain and develop a community;

- Living as part of our natural environment and so that the resource constraints of our planet are respected.

\subsubsection{An objective account of well-being with room for subjective elements}

externally observable behaviours connected with characteristic human ends: Csikszentmihalyi, "Mihaly Csikszentmihalyi on Flow," TED, http://www.ted.com/talks/mihaly csikszentmihalyi on flow.html (accessed January 7, 2011). Forgeard et al. review recent psychological studies that demonstrate that an internally sensed state of meaningfulness is an essential component of well-being: "Doing the Right Thing. Measuring Wellbeing for Public Policy," 84-85. 
The above account of what makes our lives go well for us caters for our objective intuitions about well-being. It gives us an external standard of goodness against which we can assess our choices and actions. Indeed, we can recognise the list of characteristic good human ends as one variant of the substantive good theories we encountered earlier in the discussion of subjective and objective theories of well-being.

Does it face the same challenge as the other objective theories of well-being we looked at, namely, that there seems to be no guarantee that the list of goods would bring well-being in every context and for every individual? This criticism certainly is common. ${ }^{48}$ If we agree that the ends on the list describe a characteristic human life, and if we further accept that a characteristic human life is also a good life, we are on quite robust ground against the objection. ${ }^{49}$ If we do not accept one or both of these moves, we need to deal with two difficult cases. First, what if someone achieves the ends on the list but considers that he is not made better off by it? Second, what if someone does not agree that the ends on the list are worthwhile pursuing in the first place, but thinks that some other ends would make her better off instead? I treat these cases in turn.

Imagine an employee whose job consists of serving customers. He is of the view that every customer contact is an opportunity for a mutually pleasant encounter and does his best to achieve such encounters. We could take his service attitude to contribute to the achievement of the characteristic good human end of meaningful, shared enjoyments. Surely, the encounters he has with the company's customers may be brief, but a smile, some friendly words and smooth service are likely to create a good moment for both the employee and his customer. It seems difficult to argue that having such an attitude to his job would not be part of the employee's life going well for him (and for his customers). Similarly, if the employee had the opposite, negative attitude to his job, attempting to be rude in his

\footnotetext{
${ }^{48}$ Foot, Natural Goodness, 41-43, Hursthouse, On Virtue Ethics, 211; 218-220, and Annas, The Morality of Happiness, 135-141.

${ }^{49}$ The second step is considered by many to be illegitimate. The naturalistic fallacy, or the open question argument, which in this context could be formulated as the claim that we cannot derive good human ends from characteristic human ends, is widely seen as the main problem of ethical naturalism: James Lenman, "Moral Naturalism," Stanford Encyclopedia of Philosophy, http://plato.stanford.edu/entries/naturalism-moral/ (accessed December 14, 2010).
} 
encounters with the company's customers, it would seem to be a part of his life going poorly for him. In the former case, he might still say that his life is not going well for him overall, but he would not say that his life was not somewhat better because of the encounters with his customers.

Next, consider a person who claims that her end in life is acquisition of more money and power, instead of (or in addition to) the ends on the list. It seems that under my account of well-being, three responses are possible. First, the person may initially think that she is pursuing money and power as her final ends, but upon closer analysis of her reasons and emotions, it turns out that she pursues them as a means to the characteristic good human ends. When considering her pursuit of money, she may, for example, realise that she hopes that money would allow her to engage in more enjoyable free time activities. Similarly, when considering her pursuit of power, she may realise that she hopes that power would give her more influence in the meaningful, shared projects of her work place. Second, the person may be mistaken about the types of ends that make her well-off. Third, there are several considerations about my so-far objective account that make room for our subjective intuitions about well-being and can help us understand and accommodate most well-being agendas we can imagine people to have.

The ends on the list I propose for a characteristic good human life are very broadly described: good health; bringing up the next generations so that they gain good preconditions for their flourishing and caring for the previous generation so that they get the respect they deserve; meaningful, often shared enjoyment of our existence; meaningful, often shared projects that sustain and develop a community; and living as part of our natural environment and so that the resource constraints of our planet are respected.

These ends make room for individual preferences about ways of leading our lives. I might enjoy jobs around the house and sport, while art and literature might be your favourite pastimes. To me, sharing enjoyments or projects in life is about doing so with a few close friends, whereas your interpretation of sharing requires a much wider, yet looser network of people. I greatly value my own good health, whereas you have great concern for the 
environment. I make good craftsmanship my life project, while yours is intellectual advancement. However, a little friendly gesture we exchange when our paths cross makes a positive difference to our well-being, too. My account of well-being acknowledges that we are each unique, with our unique capabilities, likes and life projects, and that no actions or choices furthering one or more of the ends of a characteristic good human life are too small to make a contribution to our well-being.

In my account, the degree of our well-being depends on the extent to which we lead a life in which we achieve the characteristic good human ends. Our achievement of them is likely to vary from one time to another for all of us, as some of how our lives go for us is decided by factors outside of our own control. Also, even if we aim for the characteristic good human ends, this does not mean that we always in practice live so that we are achieving them. Our various weaknesses, such as our limited self-knowledge and our selfishness, as well as our different starting points, make it so that a (sometimes faltering) desire to aspire towards the characteristic good human ends and a (variably) genuine effort to do so is perhaps all we can ask for in many situations of choice and action.

The above considerations strengthen and explain our intuition that the choices we make in life and the assessment of our well-being are ours and ours alone. When discussing how our rationality, emotions and sociability affect the characteristic good ends of our species, I argued for the importance of freedom already. It is worth repeating the claim, as so often objective theories of well-being are accused of undermining our autonomy. The freedom to choose how to 'live true' the characteristic good human ends and to assess to what extent we are managing to do so does of course not mean that we could not greatly enhance our well-being by consulting others when we manoeuvre through our lives; especially the views of those who know us well are likely to be very valuable. Also, our freedom increases gradually when we grow from childhood to adulthood.

In situations where not only our own well-being but that of others is at stake, all affected stakeholders, their reasoning and emotions, should be taken into account in order to reach good decisions. Most company decisions have this character, and I will have much to 
say about what this means for company decision-making in part two. For now, all I attempt to establish is that my account of well-being intends to exclude authoritarianism where someone else than individuals themselves would decide whether their lives are going well for them, not to mention be entitled to some corrective action.

In conclusion, a naturalistic account of well-being, which asserts that there is such a thing as a characteristic good human life, obviously fares strongly with respect to our objective intuitions about well-being. However, it can also cater for our subjective intuitions, because it describes well-being very broadly, acknowledges that attaining the characteristic good human goals can sometimes be challenging and, most importantly, maintains that only we can decide what kinds of things make us better off.

\subsubsection{Virtue ethics as a guideline for ethical deliberation}

There is, however, a third difficult case my account of well-being needs to deal with, which seems to me to challenge the current project more seriously than the cases of the customer service employee and the power and money seeker. Furthermore, this case is relevant even if we accept the naturalistic moves I propose, unlike the other two cases, which emerge only if we do not agree that the ends suggested describe a characteristic human life or that a characteristic human life is also a good life.

Given how broadly I describe individual well-being and given the difficulties I acknowledge accompany its pursuit for all of us, what do we do in situations in which we are genuinely uncertain about how the goodness of alternative solutions open to us compares? Sometimes, we may not see the connection between our choices and actions and wellbeing. If I choose to study philosophy instead of economics, will that bring more enjoyment and greater meaning to my life? There are situations in which two or more of the ends of a characteristic good human life conflict, and we need to prioritise which end to pursue, perhaps at cost to other ends. If I choose to live in New Zealand, I may get exciting career opportunities, but I will have less time for my family in Finland. When many people's well- 
being is at stake, solutions can make one group of people better off but another group worse off. I may be better off because of my choice of pursuing exciting projects in New Zealand, but my nephews may be worse off due to me being absent from their lives.

There are situations in which it is immediately and intuitively clear to us which solution individual well-being recommends. Consider the case of the employee with the ill mother. Despite the company's new product launch approaching, it seems that the manager's decision to give the employee time off is a pretty straightforward one. There are always other employees who can step in to help with the product launch, whereas the ill mother only has one son who can take a place on her bedside

In most cases of company decision-making, however, things are more complex. It is difficult to compare the goodness of the different solutions. Imagine a company considering whether to re-locate its production to a developing country with cheap labour, or keep production in the home country. Both solutions have benefits and drawbacks, from a wellbeing perspective. Moving production abroad would give workers in the developing country jobs and income. Continuing to produce in the home country would allow workers known to have high quality results to keep their jobs. Which solution should the company choose?

An account of well-being alone will not help us through such situations of uncertainty; we need an ethical theory that is capable of guiding our actions and choices. I turn to virtue ethics.

According to virtue ethics, ethical decision-making or deliberation is about choosing and acting as the virtuous person would. ${ }^{50}$ This definition seems to me to open up for two interpretations of virtue ethics. Let us call these the 'heavy' and 'light' interpretation.

According to the heavy interpretation, virtue ethics as an ethical theory is comparable to consequentialism - its main contender, if we start from a naturalistic theory of well-being in that it attempts to provide a decision-making procedure for determining the best solution in

${ }^{50}$ Hursthouse, On Virtue Ethics, 1, and Annas, The Morality of Happiness, 27-28. 
any given situation of ethical choice and action. ${ }^{51}$ Where consequentialism recommends that we should choose the solution with the best consequences, virtue ethics recommends that we should choose the solution that the virtuous person would choose. ${ }^{52}$ The virtuous person, in turn, is one who shows appropriate dispositions to act, or the virtues, in appropriate ways and for appropriate reasons. ${ }^{53}$

According to the light interpretation, virtue ethics is best seen as a guideline for ethical deliberation. It gives us advice on how to go about living, choosing and acting in our lives overall, and how we can better approach situations of ethical choice and action, but does not claim to provide a recipe for discovering the best solution in any situation. ${ }^{54}$ This is an interpretation of virtue ethics for which virtue theorists themselves seem to have sympathy, though they take up the challenge from consequentialism and aim to provide a decision-making procedure, too. ${ }^{55}$

If my intention was to try to establish that virtue ethics is a superior ethical theory to its contenders, and especially consequentialism, I would need to defend the heavy variant of virtue ethics so that I would be comparing like with like. Similarly, if I thought it possible to provide companies with a decision-making procedure that would allow them to determine the solution that best advances individual well-being in any given situation, I would be drawn to argue in favour of the heavy variant of virtue ethics.

My ambitions are more modest. First, I aim to argue that the light variant of virtue ethics adds to my naturalistic account of well-being by offering guidance for ethical deliberation in situations where we are uncertain about how the goodness of alternative solutions compares. In particular, 'virtue ethics light' asks us to weigh our reasons and

\footnotetext{
${ }^{51}$ A common main way to group ethical theories is to virtue ethics, consequentialist theories and deontological theories, which, respectively, maintain that we should act or behave as the virtuous person would do in the circumstances, choose the outcome with the best consequences or follow the right principled course of action. Deontology, however, does not seem to be a relevant contender for virtue ethics in this context where we start from a naturalistic theory of well-being, as well-being is not a central concept in deontological ethical theories.

${ }^{52}$ This definition of consequentialism is given by Cohen, "Equality of What? On Welfare, Goods and Capabilities," 9, though Cohen is not a consequentialist himself.

${ }^{53}$ Hursthouse, On Virtue Ethics, 11.

${ }^{54}$ Foot, Natural Goodness, 72, Hursthouse, On Virtue Ethics, 3, and Annas, The Morality of Happiness, 27.

${ }^{55}$ Foot, Natural Goodness,12-13, and Hursthouse, On Virtue Ethics, 28-29.
} 
emotions that accompany the various solutions that we are considering. We are likely to do well to choose a solution for which we have good reasons and which we feel good about. Good reasons and emotions, in turn, are such that if we and other people had them and acted according to them, well-being would be enhanced in our individual lives and in our communities. This methodology of ethical deliberation, additionally, seems to me to have some benefits over its main rival consequentialism. Finally, individual companies' circumstances are so varied that devising a decision-making procedure that would always be able to lead companies to the best well-being solution is likely to be unfeasible.

Consequently, 'virtue ethics light' is sufficient for the type of guidance I think it is realistic to give to companies.

Let us then return to the case of the company considering re-configuration of its production locations. According to 'virtue ethics light', the company decision-makers are likely to make a better decision if they not only look at the well-being effects of the alternative solutions but also weigh carefully their motives for advocating each solution, and make room for the emotions that accompany each solution. Furthermore, for all the relevant motives and emotions to surface, the decision-making process needs to incorporate the views of those whose well-being is at stake, in this case also the current and potential employees affected by the company's decision.

Starting from the well-being effects associated with the two solutions, the decisionmakers find the effects of moving production abroad tricky to assess. The company has no previous experience of operating in the region in question. Still, it looks like there are sufficient infrastructure and political stability in the country to get production going relatively quickly and smoothly. The factory would offer a job and income to a large of number of people, and would lift the community's living standards significantly. Also, learning new skills at the factory would improve the potential employees' work prospects for the rest of their lives, and would also help women in the community gain a foothold in the labour market.

The well-being effects of keeping production at home are in the decision-makers' view more predictable, but not equally big. The company would continue to provide a 
comfortable job and income for their current workers and help maintain the liveliness of the local community. However, demand for labour in the company's home region is high, and the workers' skills are transferable. Many of them would find jobs elsewhere. Additionally, management is under the impression that most of their new generation of workers find their jobs quite menial and would be likely to benefit, in the medium run, from having to look for new, more challenging positions. On balance, it seems to the decision-makers that there are good reasons to move production abroad, given the well-being effects of the two solutions.

'Virtue ethics light', however, suggests that this is not the whole story about the relevant reasons that pertain to the company's decision. It is also important that the decisionmakers assess their motives for advocating each solution. ${ }^{56}$ Despite having the exact same well-being effects, they ought to view moving production to a developing country differently if their motive is to make use of a cheap labour force than if it is to give a job and income to people who really need these to get ahead in life. Similarly, despite having the exact same well-being effects, the decision-makers ought to view keeping production at home differently if their motive is to avoid a difficult conflict with trade unions than if it is to respect the company's implicit contract with its current employees and the local community to be a committed employer.

In both cases, the former motives do not qualify as what the decision-makers ought to consider as good reasons for preferring or not preferring a solution. This is because if they and other company decision-makers chose and acted on grounds of unconditional cost minimisation, we would expect to see decisions that would tread on employees' well-being, irrespective of the well-being effects of one particular decision. Similarly, if they and other company decision-makers chose and acted on grounds of conflict avoidance, we would expect to see decisions that would not be supportive of good work communities, irrespective of the well-being effects of one particular decision.

\footnotetext{
${ }^{56}$ My distinction between the well-being effects and the motives of a decision is close to Foot's distinction between the nature of an action and the end for which an action is done: Natural Goodness, 72.
} 
Next, 'virtue ethics light' advises that the decision-makers assess the emotions that accompany each solution. ${ }^{57}$ Weighing the solution of moving production abroad, the decision-makers feel relief about not having to continue to deal with their local employee representatives with whom they have complicated relationships. They also feel good about the idea that the solution would contribute to a fairer world through offering a job and income to workers who truly need them. Weighing the solution of keeping production in the home country, the decision-makers feel relief about not having to learn a different culture's values and manners. They also feel good about the idea that the solution would allow families in the community to count on the company and plan their lives in the long term.

Again, in both cases, the former emotions do not qualify as what the decision-makers ought to consider as good emotions that lead them to prefer or not prefer a solution. This is because if they and other company decision-makers were driven to decisions by feelings of relief about not having to deal with complicated relationships or to learn other cultures' ways, we would expect to see decisions that would not be supportive of good work communities, irrespective of the well-being effects of one particular decision.

Thus, according to 'virtue ethics light', the decision-makers ought to base their decision on three things: the well-being effects of the two solutions, the motives they have for advocating each solution and the emotions that accompany each solution. In this decision, as in most company decisions, many stakeholders' well-being is at stake. Thus, the decisionmakers have the role of collecting views; not only their own motives and emotions, discussed in the above example, count, but all affected stakeholders should be heard. Once again, the decision-makers do well to choose a solution for which there are good reasons and emotions. Good reasons and emotions, in turn, are such that if they and other company decision-makers and stakeholders had them and acted according to them, well-being would be enhanced in stakeholders' individual lives and in their communities.

\footnotetext{
${ }^{57}$ Hursthouse explores the role of emotions in ethical deliberation similarly to how I do here: On Virtue Ethics, 102-110.
} 
Taking all this into account, where should the company locate its production? 'Virtue ethics light' does not say. Any of the three considerations can become decisive. This can be illustrated with one final example.

Imagine that after having weighed their reasons - both the well-being effects of the solutions and their motives for advocating them - the decision-makers come to the conclusion that they should indeed move production abroad. But then they discuss how they feel about this solution. If they have a strong enough negative feeling of remorse about betraying their local community if they are to re-locate, the decision-makers may end up deciding in favour of keeping production in the home country, despite the fact that their reasons favour re-location abroad. This is a legitimate outcome according to 'virtue ethics light.'

We have now seen that instead of providing a decision-making procedure, 'virtue ethics light' gives guidelines for ethical deliberation. Decision-makers' holistic judgement, where they consider the particular decision at hand but also think and sense how people generally should choose and act so that well-being would be enhanced, decides what solution they go for. This seems to me a richer description of ethical choice and action than that provided by consequentialism, which would advise decision-makers to focus only on well-being effects, and only on the well-being effects of the particular case at hand. ${ }^{58}$ It also seems to me a more realistic ethical theory for the company decision-making context, where individual companies' circumstances are so varied that they are likely to benefit more from open-ended deliberation guidelines than a decision-making procedure that assumes one right answer.

At the end of part one, we have a theory of human flourishing. It advises us, firstly, to live as it is characteristic for human beings to live. Secondly, it recommends that we

\footnotetext{
${ }^{58}$ Walter Sinnott-Amstrong,"Consequentialism, " Stanford Encyclopaedia of Philosophy, http://plato.stanford.edu/entries/skepticism-moral/ (accessed Nov 23, 2010).
} 
deliberate well in situations of ethical choice and action. I will now move on to consider how my ethical theory could be applied and how it is applied in the business setting.

\section{Towards parts two and three}

The examples in part one support the idea that considerations of human flourishing are as pertinent in the business setting as they are in other parts of our lives. 'Human flourishing', however, is not a term commonly used in business contexts. In the remainder of this thesis, I will use the term 'stakeholder well-being' instead to refer to a situation in which we aspire towards and achieve the characteristic good human ends. I define 'stakeholders' as the groups and individuals who are in close association with a company and can significantly affect, or are significantly affected by, its strategic decisions. ${ }^{59}$ These, in turn, are decisions that have to do with the company's objectives, how the objectives are set and revised and how the company goes about trying to achieve them ${ }^{60}$ The stakeholder groups I will consider are owners, managers (including executives), employees, customers, business partners and the local and global communities in which the firm operates.

Before getting started, I would like to underline the point that my aim is not to question the basic operating principles of a market economy, which I take to be the following.

For companies to be born and grow, in cases where growth serves stakeholder wellbeing, we need a well-functioning capital market that channels funds from savings to investment. Companies need to generate enough revenues to meet their obligations of profits payments to their owners and of loan repayments to their creditors. Also, for companies to prosper, in the sense of advancing stakeholder well-being, they need to earn sufficient revenues to reward their stakeholders at a level where they (or an alternative group

\footnotetext{
${ }^{59}$ This definition of stakeholders comes close to the definition given in Jeffrey S. Harrison, Douglas A. Boss, and Robert A. Phillips, "Managing for Stakeholders, Stakeholder Utility Functions and Competitive Advantage," Strategic Management Journal 31, no.1 (2010): 60.

${ }^{60}$ This definition of strategy follows a classic strategy theorist Kenneth R. Andrews's definition, as described in Heather Elms, Stephen Brammer, Jared D. Harris, and Robert A. Phillips, "New Directions in Strategic Management and Business Ethics," Business Ethics Quarterly 20, no. 3 (2010): 401.
} 
of equally good or better stakeholders) are happy to give their resources to the companies' use.

The prospect of profits and other economic benefits is one energising motive for entrepreneurship, innovation and aspiration in the economy, and incomes are required for stakeholders to meet their material needs and wants. Thus, a firm can implement a human flourishing conception of the good only if its changed business continues to bring in revenues that allow it to pay each stakeholder group according to its requirements. This, of course, does not preclude the possibility that stakeholders' economic requirements may change according to the type of conception of the good a company employs.

Finally, I do not claim that my conception of the good is the only worthy conception for business contexts, or even that it would be better than the existing conception employed in any given company. This can only be resolved by comparing, contrasting and testing out my conception of the good with other alternatives in specific company circumstances. What I hope to show is that implementing my conception of the good would make company stakeholders better off in important respects and hence be valuable for companies that care about their stakeholders' well-being.

\section{Part two: Company decision-making}

In part two, I will review how the good is conceived in business ethics and strategy literatures and how my conception of it as stakeholder well-being fits into these existing frameworks, on the one hand, and how it differs from them, on the other. This allows me to place my ethical theory in a framework familiar to companies and to tease out some important principles about the nature of business and company decision-making entailed by my conception of the good. I will state these principles in the respective sections in which they are developed.

\subsection{Companies and stakeholder well-being}


In part one, I illustrated aspects of my ethical theory with examples from company contexts. Though the examples seemed to flow naturally from the philosophical claims made, this alone is not enough to refute the popular belief that business (or any other social institution) is not an appropriate arena for the pursuit of stakeholder well-being, conceived in terms as holistic as mine.

This challenge, which I would like to address before tackling the more specific challenges posed by the business ethics and strategy literatures, has to do with how we in our time and society perceive the boundaries of comprehensive ethical agendas like the one I am proposing. It goes roughly like this. Even if our good ends in life were characteristic for our species and thereby had much similarity across people and settings, there is something very personal, deep-felt and complex about how we specify and realise our goals.

Consequently, pursuit of human flourishing is an appropriate concern for us in our roles as individuals or as members of intimate communities, such as the family or our group of friends. When we take on roles as company stakeholders, however, human flourishing gives way to other objectives, such as catering for our material or practical needs and wants and making money. I wish to argue against such a simplified view of business.

To understand where the perception of companies as restricted spheres of human activity is likely to originate, it is helpful to consider how company emergence and rationale is explained in economic theory. ${ }^{61}$ Without companies, productive activity - the transformation of resources to goods and services we need and want - would be arranged entirely through individuals exchanging products with each other. Firms come about to allow participants in the production process to realise greater returns (that is, more goods and services) on the resources that they contribute to joint production. Compared to a market exchange,

\footnotetext{
${ }^{61}$ The characterisation of companies that follows builds on John Hasnas, "The Normative Theories of Business Ethics: A Guide for the Perplexed," Business Ethics Quarterly 8, no. 1 (1998): 29-35, and John B. Boatright, "What's Wrong - and What's Right - with Stakeholder Management," in Ethical Theory and Business, $8^{\text {th }}$ ed., ed. Tom L. Beauchamp, Norman Bowie, and Denis Arnold (New Jersey: Pearson Prentice Hall, 2009), 71, as well as my own knowledge of economic theory as teacher of Economics.
} 
productive activity organised in firms benefits from increased specialisation, greater availability of capital, accumulation of managerial skills, enhanced stability of production and improved distribution of products. It is clear that such an arrangement is likely to make individuals better off than they would be as sole traders. Consequently, companies are in most instances formed voluntarily for the specific purpose of improving the efficiency and effectiveness with which resources are transformed to goods and services.

How are the ethics of an organisation thus conceived? The following proposal reflects a widespread, modern belief that holistic ethical agendas are not suitable for other communities than our immediate ones. When we join or interact with companies, the appropriate morality is the same as it is when we join or interact with any voluntary organisation that has a specific purpose, such as a sports club, a university or a political party: we commit to nothing more than behaving according to the ordinary ethical standards that apply to us as members of the human society (for instance, honesty, refrainment from harmful actions, obedience to law) plus the standards that are required for the specific purpose of the organisation to be achieved. ${ }^{62}$

I do not disagree with the above account of company emergence and rationale. Nor do I see any problems with the parallels drawn between companies and other organisations, such as sports clubs, universities and political parties. All are based on voluntary membership and exist for a specific purpose, which in companies' case is to produce needed and wanted goods and services. Indeed, these defining elements are well-chosen, as voluntarism underlines the importance of members' motivation for the success of a community, and purposefulness implies activity, both of which are central concepts in naturalistic virtue ethics. What I criticise in the above account, however, is the minimalistic ethics it proposes for something as significant as a company, a sports club, a university or a political party: all we need to commit to is behaving as decent people and agreeing to advance the specific purpose for which the organisation was created. As our engagement

${ }^{62}$ John Hasnas, "The Normative Theories of Business Ethics: A Guide for the Perplexed," 34. 
with such organisations is additionally voluntary, these ethical standards appear quite modest indeed.

According to the ethical theory I advance, our organisations can be vehicles for much more. Each of them constitutes one potential arena in which human flourishing or stakeholder well-being can unfold while people are voluntarily engaged in achieving the specific purpose the organisation exists for. This proposition does not change the purpose of the organisation - companies still exist in order to produce goods and services - but, as we will see, the extension of comprehensive ethical agendas to communities such as companies affects in significant ways what we hope to achieve through our activities, what we do and how. My claim is that we have equally many possibilities for pursuing the characteristic good human ends discussed in part one when we function as company managers, consumers, sportsmen or politicians as we have when we consider our personal projects or are in our roles as daughters, wives or friends.

It is then central to my conception of the good that human flourishing is not something we aspire towards just in the private spheres of our lives but it is what all parts of our lives are about - also the public parts. Naturalistic virtue ethics proposes that the proper aim of any consciously chosen human activity is flourishing. Any activity we engage in while disregarding its potential for human flourishing is an opportunity lost for our lives to go better for us. My project involves a call for a comprehensive morality that encompasses all of our activities in all the communities of which we are members.

Of possible organisations to study, I find companies particularly worthwhile investigating, because they are one main unit around which we organise our society and lives, with many of us spending a large amount of our resources, energy and time in roles that have to do with the world of business. Thus, the potential for achieving progress in human flourishing should be significant. Furthermore, although companies' choices and actions and the associated well-being outcomes, like those of any organisation, are influenced by many external forces, company decision-makers arguably have quite a large degree of freedom to implement changes designed to improve stakeholder well-being. 
We have now seen reasons to accept the following principle about the nature of business: All company activity is ethical in nature, with a potential for improving stakeholder well-being.

It is interesting to close this attempt to question the popular belief that holistic ethical agendas do not belong to all areas of our lives by noting that the belief is relatively young, and not only as a cultural perception but also as an academic position. Commentators on business, as probably commentators on other forms of our collective life, used to maintain that a comprehensive conception of the good lies at the heart of community choice and action; early writers on company strategy considered ethics a very important and the most stimulating and strenuous aspect of strategic decision-making. ${ }^{63}$

Alongside the rise of neoclassical economics in the 1970s and 80s, strategy literature evolved from its holistic beginnings into a scientifically oriented study, mainly interested in the descriptive question of how industry and firm structure, resources and constraining norms and rules affect company profitability. ${ }^{64}$ Business ethics emerged as a separate discipline during this time to respond to the need to keep the normative dimension of business on the agenda, and to attempt to develop practical guidance for how company decision-makers could go about determining the ethical course of action in any given real-life situation. ${ }^{65}$ Many argue that business ethics has failed miserably in the latter task, reducing practical business ethics to corporate social responsibility initiatives, viewed as a constraint in the periphery of business rather than as an enabler at the centre of company strategy. ${ }^{66}$ More recently, the two areas of study have come closer together, as strategy literature has

\footnotetext{
${ }^{63}$ This formulation follows a description of strategic decision-making by a seminal strategic theorist Kenneth R. Andrews. Others who held this view include Chester Barnard, Herbert Simon and Kenneth Arrow, according to Elms et al., "New Directions in Strategic Management and Business Ethics," 402. ${ }^{64}$ Ibid (pp. 402-403) and Gerry Johnson, Leif Melin, and Richard Whittington, "Micro Strategy and Strategizing: Towards an Activity-Based View," Journal of Management Studies 40, no. 1 (2003): 610.

${ }^{65}$ Elms et al., "New Directions in Strategic Management and Business Ethics," 403, and Andrew Stark, "What's the Matter with Business Ethics," Harvard Business Review, May-June 1993, 40. ${ }^{66}$ Kramer and Porter, "Creating Shared Value," 63-64, Elms et al., "New Directions in Strategic Management and Business Ethics," 403, Johnson et al., "Micro Strategy and Strategizing: Towards an Activity-Based View," 6-14, and Stark, "What's the Matter with Business Ethics," 39-41.
} 
made room for behavioural explanations of business success and understands value creation in broader terms than just company profitability. ${ }^{67}$

I will first consider the two main conceptions of the good developed in the business ethics literature in the past three decades, one focused on shareholder interests and the other emphasising stakeholder interests. These conceptions of the good differ from mine significantly, and also lead to different recommendations about how to set up company decision-making.

I will then review the conception of the good developed in the strategy literature in roughly the same time period. This is similar to the conception of the good in the shareholder theory. Compared to the theories of business ethics, which argue about how companies ought to operate, however, the strategy literature takes its task to be to describe how companies actually operate. Thus, the strategy literature provides me with an empirical model of how businesses view the good and set up their decision-making to which I can compare my own observations from case studies in part three. Additionally, the strategy literature is wider in scope; it asks not only what managers' proper objective is - the focus of the business ethics literature - but specifies who participates in decision-making and how decisions are reached. Again, the description is quite different from what my ethical theory would suggest. Consequently, a review of the strategy literature allows me to specify further principles for company decision-making for firms that care about stakeholder well-being.

Finally, I will look at an emerging body of work within the strategy and business ethics landscape which comes closer to my ethical theory than the claims of the standard business ethics and strategy literatures. Still, I will argue that even this emerging theory does not go far enough with its well-being agenda, as it continues to give primacy to profit maximisation.

\subsection{The shareholder theory of business ethics}

\footnotetext{
${ }^{67}$ Elms et al., "New Directions in Strategic Management and Business Ethics," 404.
} 
The central claim of the shareholder theory of business ethics is that managers, as company employees, should focus on what shareholders, as company owners and employers, desire. Usually, this is maximisation of shareholder wealth while conforming to the basic rules of society embodied in law and custom. ${ }^{68}$ Various powerful arguments speak in favour of the shareholder theory.

First, managers have what is called a 'fiduciary duty' to shareholders ${ }^{69}$ Firms consist of a multitude of voluntary contracts between various stakeholder groups. These contracts guarantee the security of each participant's returns on the resources they contribute to joint production. For example, employees have employment contracts that often specify work content and compensation, and suppliers have supplier contracts that commonly specify what the suppliers are to provide to the company and at what price. The argument is that for all other stakeholder groups, appropriate contracts can be crafted, except for shareholders. By definition, their reward from the resource they provide - profit earned on capital - is the residual of what is left when all other stakeholders have got their returns paid out. Requiring management of the firm for maximum profits, the shareholder theory maintains, provides the greatest available security for shareholders' returns and thereby increases their willingness to continue contributing capital. This gives rise to managers' fiduciary duty, which in the shareholder tradition of business ethics is interpreted as a duty to manage the company for profit.

Second, shareholders, through giving managers the instruction to maximise profits, end up promoting not only their own interests but other stakeholders' interests as well. ${ }^{70}$ Profit maximisation drives managers to pursue growth. If they are successful, this means that

\footnotetext{
${ }^{68}$ Milton Friedman, "The Social Responsibility of Businesses Is to Increase its Profits," The New York Times Magazine, Sept 13, 1970. Reprinted in Ethical Theory and Business, $8^{\text {th }}$ ed., ed. Tom L. Beauchamp, Norman Bowie, and Denis Arnold (New Jersey: Pearson Prentice Hall, 2009), 51. Milton Friedman is widely considered to be the father of the shareholder theory, and this is his seminal article on the topic.

${ }^{69}$ For this argument, I follow Boatright, "What's Wrong - and What's Right - with Stakeholder Management," 72-73, and Hasnas, "The Normative Theories of Business Ethics: A Guide for the Perplexed," 21.

${ }^{70}$ For this argument, I follow Boatright, "What's Wrong - and What's Right - with Stakeholder Management," 73-74, and Hasnas "The Normative Theories of Business Ethics: A Guide for the Perplexed," 22-23.
} 
there is a bigger cake for everyone to share: more employees are taken on board, salaries may rise, the network of suppliers expands, customers are offered a greater product range and so on. Moreover, shareholders are willing to bear the risk that profit as a form of return has, because they can have ownership stakes in several companies. Thus, if one of them delivers poor returns in any given year, profits from other companies are likely to compensate for the loss. This means that other stakeholder groups need to take on less risk with regard to their returns.

Third, proponents of the shareholder theory argue, the alternatives to managers maximising profits according to the shareholder instruction would be undemocratic and unwise. ${ }^{71}$ There are two economic questions in society: how to make the goods and services we need and want, and how to distribute them justly among members of society. Companies are traditionally endowed with the former task and governments with the latter. If managers start to distribute returns among stakeholders in ways different from what each stakeholder group's contract specifies, what guarantee do we have that the ensuing distribution is just? When governments decide on questions of distribution, they are responsible to electorates, there is parliamentary control over their decisions, and judiciaries exist for settling disputes. This is not true for companies. Also, managers have neither special expertise nor an obvious process for determining how much different stakeholders' interests should weigh when deciding on a distribution of returns.

Like the earlier belief that comprehensive ethical agendas have no place in a company setting, the shareholder theory of business ethics suffers from a narrow interpretation of what a business is and what it can do. The advantage of simplification is the clarity it entails. Profit maximisation is as clear an objective for company decision-making as it is possible to devise, and the arguments for the shareholder theory are compelling and consistent. Still, that clarity comes at a high cost, on the type of conception of the good I promote; one stakeholder group's interests have priority, shareholder - and as a

\footnotetext{
${ }^{71}$ This seems to be for Friedman himself the most important argument for shareholder theory. I follow his account: Friedman, "The Social Responsibility of Businesses Is to Increase its Profits," 52-53.
} 
consequence of a profit and growth orientation, other stakeholder - well-being is viewed narrowly in terms of economic benefits, and the responsibility to tackle the complex, significant potential any organisation would have to advance the characteristic good human ends through their choices and actions is taken off the shoulders of company decisionmakers.

\subsubsection{Primacy of shareholder interests versus equal concern for all stakeholders' interests}

According to the shareholder theory, shareholder interests are the interests on which managers should focus in their decision-making because all other stakeholders' interests are already defined and provided for in their contracts, because a focus on shareholder interests is likely to serve other stakeholders' interests as well, and because companies are not in a position to decide on questions of how goods and services should be distributed in a society. This arrangement, however, may lead to other stakeholders being illegitimately disadvantaged in comparison with shareholders for the following reasons.

First, the resource shareholders contribute to joint production, capital, is not as substitutable as other resources. It also comes with the credible threat that if sufficient returns are not generated in the company where capital is currently invested, it will be transferred to other uses. In comparison, any given raw material, labour or management resources are easier to substitute from the company's perspective, and yet are more difficult to transfer to other uses from the stakeholders' perspective. These differing characteristics of resources give shareholders a power advantage over other stakeholders in negotiations about returns. $^{72}$

\footnotetext{
${ }^{72}$ Thomas M. Jones, Will Felps, and Gregory A. Bigley, "Ethical Theory and Stakeholder-related Decisions: The Role of Stakeholder Culture," Academy of Management Review 32, no. 1 (2007), 141.
} 
Second, to achieve profit maximisation, stakeholder contracts are specified so that they just meet the stakeholders' minimum requirements to agree to contribute their resources to joint production. In contrast, shareholders have the right to maximum residual returns. ${ }^{73}$

Third, stakeholder contracts are usually determined for some length of time and are therefore slow to reward stakeholders for company success. In contrast, new and additional company returns, aside from what is saved for investment, accrue to shareholders. Although shareholders also bear the risk of downward changes in returns, these are likely to be less common than upward changes, as profit-maximising firms target revenue growth and cost control.

Some inequality in the distribution of returns among various stakeholder groups in general and between shareholders and other stakeholders in particular is justified. Our resources have different value to companies, and the returns we get from our contribution to joint production should reflect these differences in order for capital, labour and raw material markets to function well and for appropriate incentives for entrepreneurship and innovation to exist. Also, it may be that a return structure within which stakeholder interests are catered for through contracts and shareholder interests through the mechanism of residual returns is the best available arrangement for specifying expectations, roles and rewards. What I criticise in the shareholder theory's treatment of various stakeholder groups' interests, however, is the singularity of its decision-making focus: maximisation of shareholder wealth, subject only to law, custom and other stakeholders' contracts.

Such a focus is likely to lead managers to give insufficient weight to employees, customers, business partners and local and global communities in decisions where these stakeholders' interests are equally or more affected than shareholder interests. ${ }^{74}$ For example, a company's employment contracts may specify that employees' monthly compensation is a total compensation and includes some overtime work. If the company's

\footnotetext{
${ }^{73}$ Harrison et al., "Managing for Stakeholders, Stakeholder Utility Functions and Competitive Advantage," 60.

${ }^{74}$ Jonathan R. Macy, "Fiduciary duties as residual claims: obligations to non-shareholder constituencies from a theory of the firm perspective," Cornell Law Review 84 (1999): 1275.
} 
competitors start up production in the developing world with lower wage rates, the profit maximisation paradigm leads to pressures to increase labour productivity at home (or, alternatively, close down domestic production). Gradually, managers may expect more and more overtime from employees so as to keep company profitability unchanged. Similarly, their supplier contracts may dictate that suppliers are to follow certain environmental practices. If these are made more stringent by, say, government legislation, the profit maximisation paradigm creates pressures for managers to maintain that suppliers are to absorb the increased costs of the more rigorous environmental standards. In both cases, it seems that other stakeholders are significantly affected by the company's decisions, but their interests are not the ones driving decision-making.

According to the ethical theory I advance, everyone's interests are equally legitimate and valuable. We all share the same characteristic good human ends because we are of the same species. Our abilities, life experiences and the ways we have currently set up our communal life make it the case that we are differently endowed with potential to achieve these ends - for instance, in a company context, shareholders have more power than other stakeholders - but all of us can aspire towards the characteristic good human ends, from our different starting points. We should aim to develop our culture, institutions and practices so that this potential is cultivated rather than undermined.

In the business setting, the equal legitimacy and value of all stakeholders' interests calls for company decisions and contracts that are not based on who has most power but on whose interests are at stake. For example, performance expectations affect employees most and thus their interests are a key determinant of the kinds of work arrangements put in place. Furthermore, an equal respect for all stakeholders recommends that contractual stakeholders' interests are taken into account in company decisions and contracts in a wider and deeper way than merely ensuring that their minimum requirements for contributing their resources to joint production are met. For instance, suppliers are seen as partners in creating more valuable goods and services rather than as a source for cheap raw materials or inputs to production. Finally, an equal respect for all stakeholders encourages companies 
to consider how (and how much of) the new and additional returns accruing from unanticipated business success ought to benefit contractual stakeholders, and where the risk of various business failures should most appropriately be placed. For example, how should customers be rewarded for a good year, or punished if they do not participate in an ambitious environmental scheme a company puts in place?

We have now seen reasons to accept the following decision-making principle: Companies should give priority to the interests of those stakeholders who are most affected by any given decision.

\subsubsection{Focus on economic benefits alone versus responsibility to practice a holistic morality}

In the shareholder theory, shareholder interests are equated with profits, shareholder wealth or some other measure used for describing the economic benefits that accrue to shareholders. Thus, not only do shareholder interests have priority, but these interests are also defined in very specific terms; economic benefits are taken to be the appropriate interests for company managers to focus on in their decisions and in the contracts they offer to stakeholders.

As shareholder interests are defined in economic terms, so too are other stakeholders' interests. This is because our production system requires that the value of different resources, goods and services can be compared. The metric we use for the comparisons is money. The price of a resource, good or service is high if it is considered valuable and low if it is thought of as having little worth. It then follows that the more and better resources we have, the higher the returns we earn on them. More money, in turn, allows us to buy more and better goods and services. In short, money makes our production system go around in a transparent, predictable and, apart from the limitations discussed in the previous section, fair way.

From the perspective of the ethical theory I promote, however, such an interpretation of shareholder and other stakeholders' interests is, no matter how practical, very narrow, 
when the aim of all of our choices and actions, including those we engage in as company stakeholders, is taken to be human flourishing. The shareholder theory's focus on economic benefits alone is problematic for two reasons. First, quantities of money do not translate smoothly into proportional quantities of well-being. Second, there are components of wellbeing that money cannot buy - say, good relationships and a sense of purpose in one's activities.

One of the most debated themes in empirical economics is the relationship between wealth and well-being. ${ }^{75}$ The research looks at correlation between income and well-being across countries, across different groups of people within societies and over time. ${ }^{76}$

Many studies show that in wealthy societies, every additional unit of money adds less to people's well-being, especially if well-being is measured subjectively, than the unit before it. ${ }^{77}$ This finding is often explained by people becoming habituated to higher levels of income and consumption over time; instead of a higher income bringing higher well-being, an increase in income is required to retain satisfaction at a certain level. ${ }^{78}$ However, there are also studies that show that even if a higher absolute income does not enhance people's assessment of their well-being, a rise in income relative to peers does add to people's subjective experience of well-being. ${ }^{79}$

Although evidence for exactly what well-being effects more money has is mixed, research says as much as that the relationship between money and well-being is not straightforward. On an individual level, some people are happier than others, irrespective of the external circumstances of their lives. ${ }^{80}$ On an aggregate level, affluent countries with similar average income levels but different cultures show very different levels of subjective

\footnotetext{
${ }^{75}$ Richard Wilkinson and Kate Pickett's popular book The Spirit Level: Why Equal Societies Almost Always Do Better (London: Penguin Books, 2009) has provided a framework for much of this debate recently. Their main finding, supported by a wealth of data from around the world, is that what matters for well-being is not a high level of national income but an equal distribution of it.

${ }^{76}$ Avner Offer, "Economic Welfare Measurements and Human Well-Being," University of Oxford: Discussion Papers in Economic and Social History 34 (2000).

${ }^{77}$ Ibid., 14-16; 19-21.

78 Ibid., 22-23.

${ }^{79}$ Ibid., 21-23.

${ }^{80}$ Ibid., 24.
} 
well-being ${ }^{81}$ Moreover, they show very different performance in objective measures of wellbeing, such as the level of education, the quality of health care, or the absence of crime. ${ }^{82}$ The fact that quantities of money do not translate smoothly to proportional quantities of wellbeing raises the question how wise it is for companies to interpret shareholder interests in particular and stakeholders' interests in general solely in terms of economic benefits.

This is particularly so, as there is overwhelming evidence for the claim that other things in addition to money are required for our lives to go well for us. ${ }^{83}$ In part one, I developed one suggestion about what such other things could be, formulating it in terms of characteristic good human ends and deriving it from the way we human beings are as a species. Many other objectively or subjectively grounded suggestions for components of well-being exist, with robust roots in empirical findings: having our human rights respected, having our basic needs met, having capabilities to achieve valuable functionings, being in good health, being educated, experiencing a sense of accomplishment and competence, having strong relationships and social support, accepting ourselves, mastering our environment, having positive emotions, being engaged and motivated, and experiencing a sense of meaning and purpose in our activities all are aspects of well-being. ${ }^{84}$

When human beings' well-being so evidently consists of a great many goods, the shareholder theory's proposition that economic benefits are the appropriate interests for managers to focus on in their decision-making and in the contracts they offer to stakeholders is initially difficult to understand. But I believe it is exactly the complexity of the components of well-being that leads the theory to advocate this narrow interpretation of shareholder and other stakeholders' interests.

The thinking is roughly as follows. We know that human flourishing or stakeholder well-being is a composite matter. We also know that money can buy some important components of well-being. Businesses are the specialists in generating flows of money

\footnotetext{
81 lbid., 24-25.

${ }^{82}$ Wilkinson and Pickett, The Spirit Level.

${ }^{83}$ Forgeard et al., "Doing the Right Thing. Measuring Wellbeing for Public Policy," 79-98.

${ }^{84}$ Ibid.
} 
(through their main occupation of producing goods and services), and the comparison of different choices and actions in monetary terms is a relatively well-developed practice. Thus, businesses should focus on creating more profits, higher wages, bigger rents, increased tax payments and so on, while some other organisations, communities and individuals should figure out how to turn the money stakeholders earn from the resources they contribute to joint production into well-being, and what other things than money are required for wellbeing.

This position, represented here in the extreme, contradicts with my conception of the good. I argued earlier that my project involves a call for a comprehensive morality that encompasses all of our activities in all the communities of which we are members. We cannot compartmentalise our lives, roles and activities into private ones where we aspire towards characteristic good human ends and public ones where we do not. The responsibility to build a workplace, a partnership, a customer experience or a product that actively aims to add to stakeholder well-being is a responsibility company decision-makers cannot escape any more than can any other actors in society.

Admittedly, to know what stakeholder well-being requires in any given situation of choice and action is difficult, and often more difficult than assessing solutions from an economic perspective alone. However, complexity is a feature of ethical decision-making generally, and there is no reason why the business setting should for this reason be excused from attempting to live according to a holistic morality.

Companies' responsibility to practice a comprehensive morality calls for decisions and contracts where stakeholders' well-being features prominently. In a firm focused solely on economic benefits, decisions are made based on a comparison of the likely financial returns accruing from various solutions. Evaluating an investment in a new production facility, for instance, the company calculates the rate of return expected from that investment compared to alternative uses for its capital. In a firm concerned with stakeholder well-being, many other assessments have to be made. It needs to be determined which stakeholders' well-being is at stake in the decision, and how the various solutions are likely to affect them. 
Different stakeholders' well-being, and different types of well-being effects, need to be compared. The considerations are often qualitative and subtle. How would a new facility affect employees' work conditions and morale? Would a new facility improve the product in ways that are important for customers? What would the environmental impact of the new facility be compared to the old one?

Often, as we saw in part one, it is not enough to weigh the well-being effects associated with the different solutions. Additionally, the decision-makers need to take one step back and assess the goodness of the motives that are given for each solution and the emotions that accompany them. Which motives and emotions are such that if they and other company decision-makers and stakeholders had them and acted according to them, wellbeing in stakeholders' individual lives and in their communities would be enhanced? If a new facility is resisted because it disrupts employee routines and favoured because it allows better cooperation between employees, only the latter motive, being conducive to well-being, counts as a good motive. Similarly, if a new facility is favoured because employees feel better in a more aesthetic environment and resisted because they are afraid of changes to employee hierarchies, only the former emotion, being conducive to well-being, is encouraged and weighs into the decision.

We have now seen reasons to accept the following decision-making principle: Companies' decisions should be based not only on economic considerations but also on assessment of how various solutions impact stakeholders' well-being.

\subsection{The stakeholder theory of business ethics}

Turning to the stakeholder theory of business ethics, the central claim of this theory is that managers should manage companies not only in shareholder but in all stakeholders' interests and do so by giving stakeholders more influence in determining how the returns 
from joint production should be distributed among them. ${ }^{85}$ At least three arguments have been advanced in favour of the stakeholder theory, all rooted in ethical theories and all much criticised: the deontological argument, the consequentialist argument and the naturalist argument. ${ }^{86}$ The arguments show that although the stakeholder theory seemingly makes more room for stakeholder well-being, because it talks of all stakeholders instead of just one group of them, its suggestions about what stakeholder well-being consists in and how it can be best served are still quite different from mine.

The deontological argument for managing companies in stakeholder interests starts from the premise that people have the right to be treated as ends in themselves - as autonomous moral agents - and not as a means to an end. In a firm managed for maximum profits, stakeholders are treated as a means to the end of shareholder wealth maximisation. This is evident in the fact that while stakeholders make a contribution to joint production by giving their resources to the company's use, they usually have little say in how the proceeds of the production are to be distributed and generally get a small share of these. To take stakeholders' rights seriously, the argument goes, the company should give stakeholders a greater share of the total cake and more formal power in decisions that have to do with their benefits. $^{87}$

The consequentialist argument for managing companies in stakeholder interests, in turn, originates in the empirical fact that in a free market economy, where companies are managed for maximum profits, sub-optimal outcomes occur; the climate changes, a financial crisis occurs, or the right types of workers are not available in sufficient numbers. Such market failures arise because with no coordination of joint interests, individual companies

\footnotetext{
${ }^{85}$ Harrison et al., "Managing for Stakeholders, Stakeholder Utility Functions and Competitive Advantage," 60, Hasnas, "The Normative Theories of Business Ethics: A Guide for the Perplexed," 2526, and James A. Stieb, "Assessing Freeman's Stakeholder Theory," Journal of Business Ethics 87 (2009), 404-405, reiterate the stakeholder theory based on its original formulation by R. Edward Freeman. Elms et al., "New Directions in Strategic Management and Business Ethics," 404, discuss the increasing economic value orientation of the stakeholder theory.

${ }^{86}$ Stieb, "Assessing Freeman's Stakeholder Theory," 405-412, and Hasnas, "The Normative Theories of Business Ethics: A Guide for the Perplexed," 26-28.

${ }^{87}$ R. Edward Freeman, "Managing for Stakeholders," in Ethical Theory and Business, $8^{\text {th }}$ ed., edited by Tom L. Beauchamp, Norman Bowie, and Denis Arnold (New Jersey: Pearson Prentice Hall, 2009), 66, and Hasnas, "The Normative Theories of Business Ethics: A Guide for the Perplexed," 26-28.
} 
and managers end up choosing and acting as is optimal for them (or for their shareholders) and ignore the costs and benefits of their choices and actions to third parties. In a stakeholder-oriented world, the argument goes, there would be fewer market failures; as stakeholders' interests were given a more prominent role, company decision-makers would learn to see more of these interests as joint and choose outcomes that were better for all. ${ }^{88}$

The naturalist argument for managing companies in stakeholder interests, finally, says that we, in virtue of our humanity, are and desire to be responsible for those of our actions that impact others. Furthermore, it is characteristic for us as human beings to want to know how we can live better and to attempt to do so. Company decision-makers are no different, and thus recognise that they should take all stakeholders' interests into account in their choices and actions. ${ }^{89}$

The spirit of the above arguments is similar to the spirit of my ethical theory. Like my conception of the good, the stakeholder theory recognises each individual's value and potential to flourish, and the potential for meaningful things to happen when people come together as communities. The stakeholder theory, however, does not follow through on its humanistic tendencies. Either the arguments are left hanging in mid-air without providing a full explanation of what they would practically mean for companies as an alternative to the business reality suggested by the shareholder theory, or they give in to the conceptual framework of the shareholder theory and interpret stakeholder interests narrowly in terms of money and power. In this framework, the stakeholder theory additionally occupies the weaker ground compared to the shareholder theory, because it emphasises re-distribution of value and influence without accounting for the motives and mechanisms that allow companies to create this value and influence in the first place.

We can see the incompleteness of the stakeholder theory clearly in the consequentialist and naturalist arguments. The consequentialist argument does not explain

\footnotetext{
${ }^{88}$ Freeman, "Managing for Stakeholders," 65, and Hasnas, "The Normative Theories of Business Ethics: A Guide for the Perplexed," 30.

${ }^{89}$ Freeman, "Managing for Stakeholders," 67, and Stieb, "Assessing Freeman's Stakeholder Theory," 412.
} 
just how recognition of stakeholder interests as interdependent would allow company decision-makers to avoid market failures. The naturalist argument does not elaborate on why we have obligations towards other people and aspirations towards better lives and what implications such obligations should have for company decision-makers.

The stakeholder theory's orientation around money and power, in turn, is evident in the deontological argument. Most of us believe that people should not be treated as a means to an end in any of their roles, including those as company stakeholders. We can also agree that many companies give much influence and large rewards to shareholders (and managers) compared to other stakeholders. Still, it is not clear why the former belief and the latter observation should necessarily lead to the conclusion that companies ought to redistribute more power and money to their stakeholders.

I argued above that all stakeholders' interests have equal value and legitimacy, and company contracts and decision-making should respect this. However, the equal respect all stakeholders deserve is not necessarily best provided by redistribution of money and power. Appreciating the significance of each stakeholder group's contribution, companies that take their stakeholders' well-being seriously are likely to equalise their reward and influence structures. As economic benefits constitute just one component of stakeholder well-being, however, such companies will probably do a better job in treating their stakeholders as ends in themselves if they pay attention to the question of how the full set of characteristic good human ends is realised in their business rather than if they focus on redistribution of money alone. Similarly, redistribution of power with regard to decisions about stakeholders' benefits is likely be less respectful of stakeholders than is aiming to make all decisions so that the interests of those most affected by them are decisive.

In conclusion, the stakeholder theory makes a valuable contribution to business ethics by broadening the group of people managers should consider in their decisionmaking. As such, it alleviates the first shortcoming of the shareholder theory - that of giving shareholder interests primacy. Nevertheless, the stakeholder theory shares the shareholder theory's narrow interpretation of stakeholders' interests in terms of economic benefits, and 
carries this interpretation over to its view about how to arrange company decision-making: give stakeholders more power in determining the distribution of money. According to my ethical theory, the equal value and legitimacy of all stakeholders' interests and the responsibility to practice a comprehensive morality are not that easily taken care of. Companies should set up their decision-making so that they give priority to the interests of those stakeholders who are most affected by any given decision. Similarly, companies' decisions should be based not only on economic considerations but also on assessment of how various solutions impact stakeholders' well-being. Like the shareholder theory, the stakeholder theory of business ethics does not sufficiently acknowledge these two aspects of ethical decision-making.

\subsection{Strategy literature}

Compared to the theories of business ethics, which focus on the question of what company managers' proper objectives should be, the strategy literature sets out to describe how successful companies in the real world view the good and make decisions. The empirical models of the strategy literature are a useful comparison to me when I go through my own findings from case studies in part three. Also, the strategy literature provides a more comprehensive discussion of company objectives, who participates in decision-making and how decisions are reached. Its wide scope allows me to tease out further decision-making principles entailed by my conception of the good, in addition to the ones that surfaced through the above discussion of the shareholder and stakeholder theories.

Strategy theorists take it as their task to explain and model why some businesses are more successful than others and what this means for company decision-making. ${ }^{90} \mathrm{~A}$ successful company is defined as one that achieves superior profits or a sustained

\footnotetext{
${ }^{90}$ Chris Bradley, Martin Hirt, and Sven Smit, "Have you tested your strategy lately?" McKinsey Quarterly, January 2011, 1, https://www.mckinseyquarterly.com/Strategy/Have you tested your strategy lately 2711 (accessed February 24, 2011), and Kevin P. Coyne and Somu Subramaniam, "Bringing Discipline to Strategy," McKinsey Quarterly, no. 4, 1996, 61.
} 
competitive advantage. ${ }^{91}$ Here, then, we have a familiar interpretation of company objectives; the strategy literature agrees with the shareholder theory on the claim that profit maximisation is the appropriate focus for company decision-making. Where the shareholder theory goes on to make an argument why this should be the case, the strategy literature treats the objective of profit maximisation as an assumption.

Even if the strategy literature does less than the shareholder theory to defend the objective of profit maximisation, it provides a richer description of it; again, a successful company is one that achieves superior profits or a sustained competitive advantage. This formulation places individual companies in a market and thereby introduces two constraints on firms. First, the demand for their good or service is limited. Second, there are other companies with whom they compete to satisfy the limited demand. According to the strategy literature, then, successful businesses are those that manage to differentiate themselves from competition - by performing different activities from their competitors or performing the same activities differently - so that they capture a bigger share of the market, or expand the market to new product or service categories or new customer segments. ${ }^{92}$

Strategy theorists identify many factors that determine how successful companies are in differentiating themselves from competition. First, a company's profitability is likely to increase if it gains an advantage over its competitors, if threat of entry to its industry becomes less, if its product or service has fewer substitutes, or if the bargaining power of its suppliers or customers is reduced. A company's relative position can change as a result of what it does or what other industry players do. ${ }^{93}$ Second, unique physical, human or reputational resources can give a company a competitive advantage. The more costly such resources are to copy, the longer this advantage is likely to last. ${ }^{94}$ Third, a superior staff can give a company superior profits. Managers' (and owners') insight into the business and the

\footnotetext{
${ }^{91}$ Michael E. Porter, "What is Strategy?" Harvard Business Review, November-December 1996, 61. 92 lbid., 64.

${ }^{93}$ Michael E. Porter, "The Five Competitive Forces That Shape Strategy," Harvard Business Review, January 2008, 80.

${ }_{94}$ Kathleen R. Conner, "A Historical Comparison of Resource-Based Theory and Five Schools of Thought within Industrial Organization Economics: Do We Have a New Theory of the Firm?" Journal of Management 17, no. 1 (1991): 122, 132.
} 
competitive environment, their foresight to make good decisions, and a positive dynamic and a complementary skill set in the management team (and the company board) are all important. ${ }^{95}$ Given the quickly changing nature of modern business, empowerment of middle managers to make decisions that support the company's overall direction also makes a big difference. ${ }^{96}$ Finally, little success can be achieved unless frontline employees are able to execute on decisions made. ${ }^{97}$

From the perspective of my ethical theory, this description of company objectives and business success implies two interesting views on company decision-making, both of which have shortcomings.

First, the strategy literature describes company decision-making as a competitive exercise. Companies compete against each other for market share and innovation. But they also compete against some of their own stakeholders for bargaining power. How much can customers be charged? How little can business partners be paid? The competitive logic is applied to such questions of distributing economic benefits but also to questions of creating them. On the creation side, the central consideration with regard to stakeholders - and not only with regard to companies' external stakeholders, but also with regard to their own employees and the communities in which they operate - is how much economic benefit each stakeholder can provide and at what price. Is this employee efficient? Does this community have a good enough infrastructure? Does this supplier provide fast enough service? Is this customer worth caring about?

As long as profit maximisation is taken to be companies' objective, the competitive lens that the strategy literature uses on company decision-making seems appropriate. Companies indeed generate more profits if they are able to beat their competitors in current or future markets, or if they manage to charge customers a higher price for their products or

\footnotetext{
${ }^{95}$ Paula Jarzabkowski, Julia Balogun, and David Seidl, "Strategizing: The challenges of a practice perspective," Human Relations 60, no. 1 (2007): 8, and Coyne and Subramaniam, "Bringing Discipline to Strategy," 64.

${ }_{96}$ Bradley et al., "Have you tested your strategy lately?" 1-14, and Johnson et al., "Micro Strategy and Strategizing: Towards an Activity-Based View," 2-3.

${ }^{97}$ Coyne and Subramaniam, "Bringing Discipline to Strategy," 64.
} 
to pay their business partners less for inputs to the production process. Similarly, companies do better economically if they work with employees who cost little and deliver much.

However, I will argue below that firms interested in stakeholder well-being need to play down the competitive tone of their decision-making and adopt a more collaborative approach to their stakeholders.

Second, the strategy literature gives managers a privileged position in company decision-making and emphasises the analytical elements of the decision-making process. Of all stakeholders, it is managers who have the most appropriate skills and information to understand the cause-consequence relations between, say, entry of a new competitor, a resource shortage or middle managers' empowerment, and profitability. Moreover, an analytical process is managers' best bet to surface these relations between various enablers of performance and performance itself correctly. First, the current state and expected evolution of their own company and other players in the market have to be analysed. Second, appropriate responses need to be identified and their expected impact on profitability estimated. As the analyses focus on what players in the market do, the decisions that follow are naturally formulated in terms of which company activities to reinforce, change and develop.

As long as profit maximisation is considered to be companies' objective, the managerial and analytical focus in company decision-making that the strategy literature describes appears appropriate. It makes sense that those who are best-placed to make economically sound decisions do so. Similarly, a rigorous, well-defined analysis of relevant performance variables is likely to show best which solution is economically optimal in any given situation. However, excluding the majority of company stakeholders from decisionmaking and making little room for informal influences, such as emotional signals or stories that serve as examples or motivators, in the process is not suitable for firms that care about stakeholder well-being.

\subsubsection{Formal, managerial decision-making versus stakeholder autonomy}


With the objective of profit maximisation in mind, the strategy literature focuses on company owners and managers as decision-makers, and recommends that they base their decisions on formal analyses of the company and its competitive environment. It is unlikely, however, that companies are able to contribute to their stakeholders' well-being in the best possible ways if they approach decision-making solely in these terms. My conception of the good suggests that there are reasons for being sceptical of the strategy literature's view of both the proper participants in and the process of company decision-making.

First, as I argued in part one, it is a key element of a credible ethical theory that it allows for an intimate connection between our views about the good and what is in fact our good. Although we may sometimes be mistaken in what our well-being consists in, autonomy in defining how to attempt to achieve the characteristic good human ends is an important part of developing into flourishing individuals. Thus, company decisions that have stakeholder well-being as their objective should be based on the views of those individuals whose well-being is at stake.

This does not mean that managers or owners would not be the main decision-makers in a company. What matters from the perspective of my conception of the good is how decisions are arrived at. The issue under consideration determines which form of stakeholder participation, when it is beneficial, is most appropriate.

In some instances, managers are likely to be able to assess which solution best serves the affected stakeholders' well-being without involving the stakeholders themselves. They may, for example, be best positioned to determine the appropriate balance between long-term job security and short-term wage rises, as they have the most comprehensive information about the company's future prospects. In cases in which managers know with great certainty what the best course of action from a well-being perspective is, they do well to consult stakeholder opinion as an additional affirmation of the preferred solution. This may apply, for example, to decisions on managerial appointments. In cases in which well-being effects are significant and complex, more thorough-going methods of stakeholder 
participation are likely to be required, such as stakeholders being given responsibility for making a decision or developing an aspect of company activity. It may, for example, be wise to give teams that work with customers the responsibility for product development. Across all decisions, managers and owners should retain a coordinative and guiding role because only they see how the various practices and activities - and well-being effects - fit together.

Second, naturalist virtue ethics says that to reach good decisions, it often needs to be established not only what well-being effects different solutions have, but also how good the motives given for each solution and the emotions that accompany them are, as we saw in part one. There is no guarantee that such considerations emerge from the kind of formal analyses suggested by the strategy literature. This is because well-being considerations are made up of subtle, qualitative and sometimes uncertain ideas, thoughts and feelings. They are perhaps best expressed in stakeholders' informal encounters with each other. In any case, they are difficult to reduce to variables that can be causally analysed.

This does not mean that the formal aspects of a company's decision-making process would be less important. What matters from the perspective of my conception of the good is that in decisions where stakeholder well-being is at stake, also informal influences enter into the decision-making process.

New types of analytics, such as workshops with different stakeholder groups or sociological methods of gaining information, can be introduced. ${ }^{98}$ More importantly, managers and owners do well to involve themselves in stakeholders' daily lives. People are more likely to tell more and more honestly about what makes their lives go well for them when they have the opportunity to express themselves in ways characteristic for them and in an atmosphere of trust. Good stakeholder relations take time and effort to build but allow

\footnotetext{
${ }^{98}$ I was involved in testing such decision-making methods in my previous job in the strategy department of a large media company. My task was to coordinate a sociological study of Finnish youth's media habits. A project team of 20 people, made up of employees from different divisions and organisational levels, spent 2-3 days each with youngsters, observing their daily lives and talking to them. The field workers wrote down their observations, took photos and shot video. A shared list of tag words was developed and applied to the materials to identify common observations across cases. Insights from field work were combined with traditional consumer analyses to inform new product development.
} 
managers and owners to gain a much richer understanding of how stakeholders truly think and feel about company decisions and why. Finally, managers and owners should dare to exemplify that they, too, are willing to venture beyond the analytical territory. Sometimes, a powerful personal story, for example, can motivate a work community and give an organisation a shared direction much more effectively than even the most robust analysis.

We have now seen reasons to accept the following decision-making principle: Companies should engage stakeholders in decision-making that affects their well-being and make more room for informal influences in the decision-making process.

\subsubsection{Competitive approach to stakeholders versus search for shared meanings}

With the objective of profit maximisation in mind, the strategy literature describes company decision-making as a competitive exercise. If one industry player wins, others lose. Companies bargain with their customers and business partners. There is a calculative aspect to the relations between owners and managers on one hand and employees and communities on the other. It is unlikely, however, that companies are able to contribute to their stakeholders' well-being in the best possible ways if they approach decision-making primarily in such competitive terms. The nature of well-being and my conception of the good both suggest reasons for being sceptical of the strategy literature's view of stakeholder dynamics.

First, the nature of well-being is not competitive. Well-being is not exclusive; if one company's stakeholders in an industry achieve more well-being, this does not mean that other companies' stakeholders need to be worse off. Rather, different stakeholders' wellbeing is often interdependent. For example, customers' encounters with a company are likely to be positive only if customer service employees are friendly. Similarly, the local community's health is likely to suffer from a company's irresponsible environmental practices. Also, different stakeholders' well-being is often mutually reinforcing. For instance, if a company's managers and owners show inspirational leadership, their employees are 
likely to be more motivated for their work. Similarly, if a company is a part of an innovative network of businesses, this is likely to make developing their own product easier.

Second, much potential well-being is likely to be lost if stakeholders are not approached with a collaborative attitude. In part one, I completed my list of characteristic good human ends with some ideas from philosophers of meaning. I suggested that a big part of what it is like to be a flourishing person is to have experiences of meaningfulness, which originate in the positive interactions we have with each other and the world. Projects and enjoyments that stakeholders are able to realise together in a cooperative business setting say, managers and employees making a new strategy together, or key customers participating in a product development initiative - create shared, meaningful experiences that are an important constituent of our well-being. Such experiences are likely to be much fewer if stakeholders see themselves primarily as a brick in the company's cost-benefit game.

We have now seen reasons to accept the following decision-making principle: Company decision-makers should be less concerned about how stakeholders can help the company win over competition and focus more on collaborating with stakeholders on issues affecting their well-being.

As is clear from the above, my ethical theory entails quite a different view on the participants, process and dynamics of company decision-making than the one suggested by the strategy literature. I do not claim, however, that the strategy literature is then mistaken; its recommendations are merely insufficient for companies that are interested in stakeholder well-being. Strategy theorists say what determines a firm's success in achieving its profit maximisation objective. These determinants apply to stakeholder well-being oriented companies as much as to any other; they, too, need to generate revenues that are greater than costs. Moreover, the strategy literature does a good job of explaining the basic operating principles of a market economy, which I do not wish to challenge with my ethical theory. First, the limited nature of demand explains why entrepreneurship, innovation and aspiration are important; customers can always choose an alternative provider to meet their needs. Second, the existence of competition explains why stakeholders' requirement of a 
certain level of returns for the resources they provide to joint production is credible; they can always sell their resource to an alternative firm. From the perspective of my ethical theory, however, economic considerations are only one aspect of company decision-making.

\subsection{An emerging theory}

Being based on real-life data and observations, the strategy literature shows that companies combine elements of the above three theories of business - the shareholder and stakeholder theories and the theory embedded in the strategy literature - in their decisionmaking. The shareholder theory and strategy literature's profit maximisation thesis remains the overall guideline companies operate by so that when profitability and other goals conflict, the former is decisive. ${ }^{99}$ Still, other stakeholders' economic interests are also taken into account, as recommended by the stakeholder theory. First, shareholders often agree to managers favouring some other stakeholder group than themselves, as happens when employees are rewarded more than their contracts specify or given guarantees of job security. ${ }^{100}$ Second, shareholders give managers a great degree of freedom in conducting daily business decision-making and in drafting stakeholder contracts, without demanding guarantees that they constantly follow the profit maximising paradigm in these activities. ${ }^{101}$ Third, employees are given influence in decisions that affect their benefits through management's cooperation with trade unions. Company decision-making is set up to support maximisation of profits and other stakeholders' economic interests, as described. We can call this 'the dominant model of business decision-making'.

\footnotetext{
${ }^{99}$ Kramer and Porter, "Creating Shared Value," 64, James Hine, and Lutz Preuss, "Society is out there, organisation is in here: On the perceptions of corporate social responsibility held by different managerial groups," Journal of Business Ethics 88, no. 2 (2009): 387-388.

${ }_{100}$ Macy, "Fiduciary duties as residual claims: obligations to non-shareholder constituencies from a theory of the firm perspective," 1275.

${ }^{101}$ Richard Marens, and Andrew Wicks, "Getting Real: Stakeholder Theory, Managerial Practice, and the General Irrelevance of Fiduciary Duties Owed to Shareholders," Business Ethics Quarterly 9, no. 2 (1999): 281.
} 
The dominant model, however, is coming under increasing criticism. ${ }^{102}$ In recent debates over the financial crisis, rising income inequality and unemployment, and the environmental burden of human activity, companies have been perceived as greedy, free riding on the wider communities in which they operate. The criticism that comes from the ranks of strategy theorists and business ethicists is not targeted at the objective of profit maximisation but at ways companies have gone about trying to achieve it: aiming for greatest possible short-term returns through strategies such as enticing consumers to buy more and more, use of cheap ingredients in the production process, personnel reductions and relocation of activities to low-cost countries. ${ }^{103}$

The appropriate corrective for companies, this emerging body of work suggests, is to move away from a short-term profit maximising mind-set to creating shared long-term economic and social value both for shareholders and for the communities of which firms are a part. Measures such as conceiving products in new ways and offering them in new markets, building more local clusters of economic and social activity, redefining stakeholder relationships in mutually beneficial ways, and giving a greater voice to long-term company owners are put forward as possible ways of re-establishing the credibility of business. ${ }^{104}$

The above constructive criticism of the dominant model of company decision-making seems to me a very promising start for a new agenda for strategy literature and business ethics and is close in its recommendations to my ethical theory. It advocates a view on which all stakeholders' interests are taken into account, interests are interpreted to be economic and social, and good outcomes can only be reached if companies and communities work together. There are, however, two points of divergence between this emerging theory and my conception of the good.

\footnotetext{
102 Two recent influential criticisms of the dominant model come from Michael E. Porter of Harvard Business School and Dominic Barton of McKinsey \& Company. The following builds on their views. ${ }^{103}$ Kramer and Porter, "Creating Shared Value," 64-66, and Barton, "Capitalism for the Long Term," 86-87.

${ }^{104}$ Kramer and Porter, "Creating Shared Value," 65-67, and Barton, "Capitalism for the Long Term," 90.
} 
First, the emerging theory's understanding of economic and social benefits is still narrower than my list of characteristic good human ends described in part one. According to the emerging theory, all benefits, including social benefits, need to be measurable in economic terms so that firms can compare different solutions according to the familiar costbenefit logic. Consequently, only tangible goods, such as health, improved nutrition, greater education and skills, better housing and less environmental damage, can be included as benefits in the account. ${ }^{105} \mathrm{I}$ have argued that our well-being consists of many projects and enjoyments that have intangible aspects to them - say, a positive encounter between a company's employee and a customer, meaning that resides in solving a practical or an intellectual problem in how a firm operates, or a shared celebration of an achievement. The comparative goodness of such projects and enjoyments cannot be measured in price terms. Instead, when assessing different solutions, company decision-makers need to make holistic judgements about the quantifiable and non-quantifiable well-being effects of each solution, and the goodness of the motives and emotions that accompany them.

Second, the emerging theory does not question profit maximisation as the objective of business at which companies should aim in choosing one course of action over another. ${ }^{106}$ My ethical theory considers stakeholder well-being to be the objective of business. As such, it sometimes recommends a solution that is not profit-maximising, not even over the longer term, such as giving superb customer service even if it is unlikely to lead to repeat business or peer recommendations, ending a beneficial supplier relationship because the supplier's ethical standards are not quite high enough or showing flexibility towards an employee who is leaving because of her past loyalty.

It is worthwhile examining this latter difference between the emerging theory and my ethical theory in a bit more detail, as explaining what happens when profit maximisation conflicts with stakeholder well-being is a key challenge for the type of conception of the good

\footnotetext{
${ }^{105}$ Kramer and Porter, "Creating Shared Value," 67-68.

106 Kramer and Porter, "Creating Shared Value," 75, and Barton, "Capitalism for the Long Term," 88-
} 89. 
I promote. ${ }^{107}$ Earlier, I defined the purpose of business to be production of needed and wanted goods and services. The emerging theory probably agrees with this purpose. However, the two theories are likely to disagree if we probe them with further 'why' questions.

Consider two companies, a ferry operator which agrees with the emerging theory's conception of the good and a bike wheel maker who agrees with the type of conception of the good I advance. If the ferry company managers are asked why the firm provides ferry crossings - beyond the fact that there is a market for them - they answer 'because ferry crossings generate a profit.' Similarly, if they are asked why they choose one ferry schedule over another, they answer 'because it is more profitable'. Turning to the bike wheel maker, if he is asked why he makes bike wheels - again beyond the fact that there is a market for them - he answers 'because I know how to make the kinds of wheels that add to my customers' enjoyment of cycling, I want to create bike wheels that come with a story and a great service, and this is a job I like.' Further, if he is asked why he uses wheel parts from a certain manufacturer but not from another, he answers 'because they make for better bike wheels.'

Thus, according to my ethical theory, while fulfilling their purpose of providing needed and wanted goods and services, companies realise the objective of advancing stakeholder well-being, and that objective provides a motive why one course of action or solution is the preferred one in any given situation. For the emerging theory, and for other theories that consider profit maximisation as the appropriate overall guideline for company decisionmaking, fulfilling their purpose as providers of goods and services allows companies to realise the objective of making profits. This does not seem to me a necessary outcome, but merely the dominant one. We can identify the objective governing a company's choices and actions to be stakeholder well-being and say that stakeholder well-being should prevail in situations in which it conflicts with profit maximisation, and yet remain loyal to the operating

\footnotetext{
${ }^{107}$ I encountered this challenge in all my case studies and in most discussions I have had about my thesis with colleagues and friends.
} 
principles of a market economy. As I mentioned earlier, the ability to pay each stakeholder group according to its requirements is a constraint companies operate under, but this is not to say that profit maximisation should be their objective.

We have now seen reasons to accept the following principle about nature of business: Stakeholder well-being, rather than profits, should be the objective of business and the motive for choosing one solution over another.

Incidentally, if a company takes stakeholder well-being as its objective, it may often end up making the same choices as a company who takes its objective to be profit maximisation. This is especially so under the emerging theory, which encourages a shift of time perspective from quarterly profits to the long-term economic health of a company. In many cases, economic and well-being considerations pull firms in different directions only because the former are viewed from a short-term perspective. For example, an accommodative personnel policy is likely to be costly in the short run but may make sound economic sense in the medium to long run. Similarly, improvements in product quality may reduce customers' need to come back in the short run but increase the chances that they will return to the company when they do need a new or a related product.

There is compelling evidence that companies that take stakeholder well-being seriously can show a superior long-term economic performance to those who do not. ${ }^{108}$ This is because a firm concerned with the good attracts a greater number of stakeholders, who additionally are more loyal and willing to reveal valuable private information about their preferences to the company. ${ }^{109}$ Furthermore, some characteristics of today's Western societies help companies that show sensitivity to stakeholder well-being to do well

\footnotetext{
${ }^{108}$ Studies that have been done on the relationship between stakeholder orientation and financial performance are discussed in Harrison et al., "Managing for Stakeholders, Stakeholder Utility Functions and Competitive Advantage," 59-60, and exemplified by Shawn L. Berman, Andrew C. Wicks, Suresh Kotha, and Thomas M. Jones, "Does Stakeholder Orientation Matter? Relationship between Stakeholder Management Models and Firm Financial Performance," The Academy of Management Journal 42, no. 5 (1999): 488-499. Many examples of companies that have created a positive relationship between the two are discussed in Kramer and Porter, "Creating Shared Value," and Rajendra S. Sisodia, David B. Wolfe, and Jagdish N. Sheth, Firms of Endearment (New Jersey: Wharton School Publishing, 2007).

${ }^{109}$ Harrison et al., "Managing for Stakeholders, Stakeholder Utility Functions and Competitive Advantage," 50-60.
} 
economically. These include the generally poor reputation of business, which makes ethical companies stand out, a wealthier customer base that can afford to care, easier access to information about companies and their products, and a heightened environmental sensitivity that spills over to a more general interest in ethical business practices. ${ }^{110}$

To conclude part two, the discussion above has revealed that my conception of the good entails the following principles about nature of business and company decision-making:

- All company activity is ethical in nature, with a potential for improving stakeholder well-being.

- Companies should give priority to the interests of those stakeholders who are most affected by any given decision.

- Companies' decisions should be based not only on economic considerations but also on assessment of how various solutions impact stakeholders' well-being.

- Companies should engage stakeholders in decision-making that affects their wellbeing and make more room for informal influences in the decision-making process.

- Company decision-makers should be less concerned about how stakeholders can help the company win over competition and focus more on collaborating with stakeholders on issues affecting their well-being.

- Stakeholder well-being, rather than profits, should be the objective of business and the motive for choosing one solution over another.

I will now turn to my case studies to show that these principles, and my ethical theory from part one, are applied and considered relevant by real-life companies.

\section{Part Three: Case studies}

${ }^{110}$ Sisodia, Wolfe and Sheth, Firms of Endearment, xxvii and 265. 
In part three, I will look at to what degree and how four Wellington-based companies implement the type of conception of the good and decision-making principles that I have argued for in parts one and two of the thesis. Three of the case studies provide evidence that there are companies that resist the dominant model of business decision-making and consider humanistic alternatives to it both plausible and practical. One of the case studies suggests that some companies that follow the dominant model have good reasons to be and are instrumentally interested in stakeholder well-being. The case studies also help me to identify some practices with respect to stakeholder well-being that seem to be common to companies that follow my kind of ethical theory, independently of company or industry specifics.

\subsection{Introduction to the case studies}

I conducted interviews with the following companies: Cook Strait ferry operator Interislander, bike wheel maker Wheelworks, IT service company Enspiral, and non-profit organisation the 42collective.

- Interislander is a medium-sized company with annual revenues of $\$ 150$ million. It employs 560 people and provides passenger and cargo transport across the Cook Strait on three ferries. Interislander is a division of the economically challenged stateowned enterprise KiwiRail Group.

- Wheelworks is a one-man company owned, managed and run by Tristan Thomas. He handcrafts high quality, tailor-made bike wheels for the New Zealand cycling market in his workshop in Lyall Bay.

- Enspiral is a young, small yet fast-growing start-up. It currently employs $25-45$ people (depending on how we define 'employee') and provides software solutions mainly for New Zealand companies and organisations. Enspiral's vision and organisational 
model are unconventional and very people- and community-centred. Staff decide for themselves what projects and customers they work with and at what price, and the Enspiral management facilitates their cooperation and encourages their ethical ambitions.

- Conscious Consumers is one operational arm of the non-profit organisation the 42collective. It certifies Wellington and other New Zealand cafes for following ethical practices according to its self-developed badge system (for example if a café follows Conscious Consumers' recycling requirements, it can earn the recycling badge). The 42collective and Conscious Consumers are managed by a committee and operated mainly by volunteers.

The format and content of my meetings with these companies varied. With Interislander, I did a workshop with the whole management team on the company's current ideas of the good and decision-making and how these would potentially change if Interislander were to approach their operations from a stakeholder well-being perspective. Another workshop on staff engagement with two members of the management team followed. The meetings with Wheelworks, Enspiral and the 42collective could best be characterised as exchanges of thoughts between the companies' managers and myself on ideas of the good and business decision-making as they see it, and as I see it.

Wheelworks, Enspiral and the 42collective were chosen as case studies due to their ethical profiles. I assumed they would equip me with examples of how a conception of the good and decision-making principles like mine could work in practice. This assumption proved correct. Interislander was selected as a representative of companies that follow the dominant model of business decision-making. This also turned out to be the case. I was impressed by the openness and interest with which all four companies approached the exercise. They all have advanced thoughts about the good, and about the opportunities and challenges they as company managers have in realising it. 
My most important finding from the empirical work is that the case studies show that it is possible for real-life companies, which are subject to the constraints of the market, to have a humanistic conception of the good, and to be successful, both in promoting stakeholder well-being and in doing well economically. Wheelworks, Enspiral and the 42collective all operate significantly differently from what the dominant model of business decision-making would recommend. Their primary objective is people's well-being instead of profit maximisation, and their decision-making is accordingly people-centric, not profit-centric. Despite their lack of a profit orientation, these companies deliver positive returns. Interislander, in turn, is profit-oriented. Still, stakeholder well-being interests the company, mainly because it sees that engaged and collaborating staff, in particular, holds the key to an improved economic performance.

According to my ethical theory, stakeholder well-being is valuable for its own sake. Consequently, the results from interviews with Wheelworks, Enspiral and the 42collective are particularly interesting to me. However, my work with Interislander shows that stakeholder well-being may also be valuable as a strategy towards profit maximisation. I will now look at each firm's attitude and approach to stakeholder well-being and company decision-making to substantiate these overall findings.

\subsection{Interislander}

Interislander's objective, according to the company's management, is sustainable profitability. This is dictated by the troubled economic situation, over a long period of time, of the KiwiRail Group of which Interislander is part. To increase its customer numbers and freight volume, Interislander aims for excellence in customer service and a spotless safety record. To increase its revenues per crossing, the firm attempts to optimise the use of its ferry fleet, for example through careful management of scheduling and of the cargopassenger ratio. To keep costs in check, the company offers only the types of ferry services (and add-ons) for which customers are willing to pay. Of the determinants of success under 
the company's own control, Interislander management sees the company's ability to create a unified, progressive culture, to meet or preferably exceed customer expectations and to exercise strict cost control as critical.

In company decision-making, owners' interests are primary. Decisions are based on economic considerations. According to the General Manager Thomas Davis, when what would be most profitable and other aspirations conflict, profitability decides which solution is chosen. He used the example of choice of fuel to illustrate this point. It would be better for the environment the slower the ferries operated and the better the grade of fuel were used. However, New Zealanders are not particularly environmentally aware and the likelihood of a public outcry about a company's environmental practices is small. Thus, Interislander has been considering switching to a cheaper grade of fuel on profitability grounds.

Company decisions are prepared by members of the management team. Comparison of the costs and benefits of different solutions, quantified where possible, is the dominant approach to analyses. Decisions are made in management team meetings, or in significant matters, by the KiwiRail board. The management's approach to stakeholders reflects the company's heightened concern for sustainable profitability. For instance, employees' wage demands were perceived as unrealistically high in the company's current economic situation. When we were discussing the service offer, I asked whether the ferries could offer higher quality food prepared from local, fresh ingredients and whether the rest areas in harbours could be more aesthetically decorated. According to the management, such services, which would enhance the customers' experience of the Cook Strait crossing, are continuously considered, but can be introduced only if they leave profitability unaltered or lead to greater profitability.

In our discussions, members of Interislander management showed interest in stakeholder well-being. No one in the management team wished to contest my proposition that all company activity is ethical in nature, with a potential for improving stakeholder wellbeing. When we talked about the motives for aiming at it, however, it was clear to me that the management viewed stakeholder well-being more in instrumental terms than as a realistic or 
desirable business objective in itself. They thought that it would be good if customers enjoyed the ferry crossing more because this would increase customer numbers and loyalty. They also thought that it would be good if employees experienced their work as a shared, meaningful project because this would lead to better customer service, which again would increase revenues. Employees' experience of their work proved to be an especially interesting discussion topic, because this stakeholder group is most directly under the company's influence.

When we talked about the company's challenges, limited trust between the onshore administration and some offshore staff and difficulties in aligning the middle management behind the top management's objectives were mentioned. The management also brought up presence of sub-cultures within the organisation, with some individuals demonstrating willingness to build a winning company together and others resisting change. These employee-related challenges manifest themselves in customer service, with regard to which the management saw improvement potential.

When we discussed ways of tackling the challenges, economic incentives came up; pay is an important driver of employee performance. Interislander management considered employee engagement in company decision-making and the company demonstrating a more collaborative attitude to its employees to be important ways of positively affecting employees' experience of their work. This, indeed, is what my conception of the good would recommend. We talked about how the management could go about engaging and collaborating with staff better. Giving teams of employees responsibility for some well-defined company development projects, inviting employees who have already demonstrated change leadership to work with the management, and the management increasing their informal interactions with staff were seen as promising initiatives.

In conclusion, despite the profit focus dictated to them and their consequent commitment to the dominant model of business decision-making, Interislander management clearly acknowledged the value of stakeholder well-being. Furthermore, the managers 
appeared to consider changing company decision-making in ways suggested by my ethical theory to be a relevant strategy for enhancing employees' experience of their work.

\subsection{Wheelworks}

Wheelworks' objective, according to the owner-manager Tristan Thomas, is to make unique bike wheels and offer them with superb service. This is a niche Tristan saw in the New Zealand cycling equipment market some years ago. The products then available were cheap but of mediocre quality, were offered with little knowledge of cycling and were accompanied by poor customer service. He set out to improve the New Zealand cycling equipment market for enthusiasts like himself. Still, economic considerations matter, too; Tristan needs to make a living out of his business. Additionally, the levels of profitability and growth the company achieves serve as one measure of Wheelworks' success. The most important measure of success to Tristan, however, is how good he can feel about the day's work - the wheels made and the customer service given - when leaving his workshop in the evening.

Wheelworks contributes towards its customers', Tristan's own and the Wellington cycling community's well-being in many ways that are harmonious with my conception of the good. The centrality of stakeholder well-being to Wheelworks' operations is further reflected in company decision-making, which largely follows the principles I laid out in part two.

Wheelworks' product encourages a healthier lifestyle, if it causes people to ride more. Moreover, with Wheelworks wheels on their bikes, cycling enthusiasts can ride faster and more smoothly and gain credibility and prestige among their peers. Riding becomes a more enjoyable hobby for them for these reasons. The knowledgeable service Tristan provides leads him and his customers to have interesting discussions about cycling equipment and its desired performance, and about individual riding preferences. Furthermore, given their shared interest, Tristan and his customers may have good conversations about cycling that go beyond the mere equipment purchase. Tristan mentioned, for example, that he has 
noticed that when he closes the workshop to attend a cycling race, his customers follow the Wheelworks racing team online during his absence and comment on events afterwards.

When the cycling-related aspects of his customers' lives are made better because of Wheelworks, Tristan's own well-being is also enhanced. He described working with Wheelworks - and especially the customer encounters - as what he loves to do. He said that he sometimes has almost a bad conscience about making a living from his favourite hobby. At the moment, Tristan considers that Wheelworks provides him with sufficient challenge and development opportunities. He enjoys the flexibility of being an entrepreneur: if he sees value in going on a bike tour and closing his workshop for a week, so he does, understanding that this means more work in the week after. Being his own boss and especially taking the full responsibility for all his choices and their consequences seemed to motivate Tristan greatly about his work with Wheelworks.

Finally and not surprisingly, given the collective well-being dynamics at play, Wheelworks is actively present in the Wellington cycling community. Tristan sponsors and manages a racing team that brings together some of New Zealand's leading nonprofessional riders. The team practices together and participates in cycling competitions around the country. Wheelworks Racing has in short time grown into a bigger community than just its competitive riders, with activities and friendships built around the hobby of cycling. There is discussion in the team of 'giving back' to the wider New Zealand cycling community by, for example, doing junior development. ${ }^{111}$ The company's role is to sponsor Wheelworks Racing and Tristan gives much of his free time and expertise to the team's use.

Moving on to company decision-making, the close well-being ties between Tristan, his customers and the Wellington cycling community are evident also here. Either customers or Tristan's interests are primary, depending on whose well-being is at stake in any given decision. For example, Tristan said that how much cycling talk takes place between him and his customers depends on each customer's preferences. When it comes to the schedule of

\footnotetext{
${ }^{111}$ Roadcycling New Zealand, "Team Overview: Wheelworks Racing," http://www.roadcycling.co.nz/TeamTalk/team-overview-wheelworks-racing.html (accessed April 12, 2011).
} 
delivering the wheels, in turn, Tristan determines his own pace of working. Decisions are based on well-being considerations within economic constraints. For instance, Tristan uses wheel parts that make for durable, high-performing wheels but charges his customers accordingly.

Company decisions are made by Tristan, but he takes into account his customers' and the cycling community's opinion where this is relevant for achieving the best well-being outcomes. For example, many product and service development ideas come from existing and potential customers in the community. Decision-making is informal; Wheelworks responds to and evolves based on Tristan's ambitions and the needs and wants of his existing and potential customers in the cycling community. Tristan's attitude towards his stakeholders is very collaborative. If his stakeholders are not better off because of Wheelworks, Wheelworks will not serve his own well-being either. I got the impression that the most significant well-being effects for Tristan are the shared ones.

In conclusion, Wheelworks operates according to a humanistic conception of the good - though Tristan himself would not make a point of it. Still, considering what it requires and implementing it is by no means easy. Two challenging aspects surfaced in our discussion.

First, there is the question of just how enhancing of well-being a company's product or service is and ought to be. Do bike wheels that may cost up to $\$ 2,000$ make Wheelworks' customers' lives go better for them in significant respects? Is it acceptable that some people in society spend $\$ 2,000$ on a set of bike wheels, when other people do not have their basic needs met? In the case of Wheelworks, our exchange of thoughts on this topic ended with a consensus that the service experiences Tristan gives to his customers and the positive ways in which he and the company contribute to the Wellington cycling community seem to provide a strong justification for Wheelworks' existence, from an ethical point of view.

Our exchange on this topic reflects the idea that the list of characteristic good human ends specified in part one is wide. For some, expensive bike wheels may give much wellbeing. The exchange also underlines the point that human flourishing admits of degrees. 
Even if Wheelworks' product might not be as well-being enhancing as some other companies' products, the company achieves much well-being through its service experiences and community contributions. This may well be 'good enough'. Finally, the exchange showed to me that having good motives for their choices and actions can be very important for business decision-makers. Tristan seemed to feel strongly about the topic, and it clearly mattered to him that Wheelworks' operations could be justified from the perspective of stakeholder well-being.

Second, there is the question of how to balance well-being pursuits against economic constraints. Tristan wants and needs to make a living out of Wheelworks. He wishes to see his company grow and earn profits, because this signals to him that he is still passionate about what he does, challenged by his job and spending his time and energy well compared to alternatives. When economic benefits serve these two purposes, and yet when Wheelworks is primarily about stakeholder well-being, all kinds of practical conflicts ensue for Tristan. How to balance between a hobby and a job? How to distinguish between a friend and a customer in the same person? How to share his knowledge about cycling equipment in the community without giving away business ideas to other potential entrepreneurs?

Tristan was very aware of such practical conflicts and had clear thoughts about how to solve them. He emphasised the importance of self-management and of creating trust between him and his existing and potential customers in the cycling community. This meant, for example, that he would not take the initiative of discussing Wheelworks when in his community role. It was evident that despite the trade-offs between Wheelworks' well-being and economic considerations, Tristan wanted it no other way; the community nourishes his passion for cycling and hence, for Wheelworks.

\subsection{Enspiral}

Enspiral's objective, according to two leaders of the company, Josh Forde and Sam Rye, is to find people who want to create positive change in their communities and empower 
them to do so. Enspiral develops software solutions that further a social or an environmental cause, and has two business areas: its own start-up projects and client projects. Josh and Sam described profits as 'not the point', but a natural consequence of adding value to communities, a neutral yard stick of how the company is doing compared to competition and a tool for focusing their work. Profits also enable growth. Yet here, too, what matters more than that Enspiral grows is that the Enspiral vision and people, or 'Enspiralites' as they were referred to, grow. Success was defined as increased ability to achieve positive change.

During our discussion, the concept 'good' in various forms kept reappearing. Engagement in valuable free time pursuits was mentioned as a recruitment criterion, and people are promoted partly on the basis of their morale. Particularly worthy projects or exemplary behaviours get the leadership's attention. An important personal driver for Josh and Sam to work with Enspiral was to be able to achieve good things with their time, energy and expertise. Implicit in these comments seemed to me to be a largely humanistic understanding of the good. Nevertheless, Josh and Sam did not want to give an explicit definition of Enspiral's conception of the good; the diversity of people means that there is a diversity of goods, and the good evolves as the world evolves.

Certainly, Enspiral helps its clients, communities, the environment and 'Enspiralites' flourish in ways suggested by my conception of the good. The centrality of stakeholder wellbeing to Enspiral's ambitions and activities is further reflected in company decision-making, which largely follows the principles I laid out in part two.

The software solutions that Enspiral designs for its client organisations, most of which are start-ups and non-profits, have many well-being effects. Efficient technology allows the clients to focus on their core activities instead of administration. The software may facilitate better communication within the client organisations and towards their external stakeholders. Often, Enspiral staff and client staff work closely together on projects that both parties find enjoyable and meaningful. An example of a project with all these outcomes is Enspiral's making software with and for an organisation that helps people quit smoking. Enspiral's own software solutions, in turn, enhance the well-being of communities and the environment. 
Often, they aim at enabling consumers and producers to adopt new, more ethical behaviours. An example of a project that has both social and environmental benefits is the development of software that reduces inefficiencies in distributing organic farming produce directly from small farmers to consumers. ${ }^{112}$

Turning to the well-being of its own people, 'Enspiralites' are individuals who want to create positive change in their communities. When they come to Enspiral, or when Enspiral finds them, they know what they want to do or, at least, what types of things they wish to achieve with their working lives. Enspiral's role is to empower them so that they can focus on what they are good at and interested in. I got the impression from our discussion that Enspiral's leadership has a dual role with regard to its employees' well-being: giving them freedom and responsibility and creating an inspirational work community.

According to Josh and Sam, Enspiral can be described more appropriately as a network of relations than as a company. 'Enspiralites' are like entrepreneurs under a common umbrella. They decide which projects to work on, how much to charge for their work, with whom to cooperate, where and when to work and what help they require from Enspiral. The corollary of having so much freedom is that there need to be clear performance expectations: 'Enspiralites' have to show a development path and results in the work they do to remain a part of the company. Such a framework is meaningful and enjoyable for the kinds of high-performing, creative people Enspiral attracts and wants to attract. Sam summarised the attitude their people have: work is a way of life. This implies, also, that work community is important for 'Enspiralites'. The leadership was very aware of their task of building and encouraging a community where people express ideas freely, take the pain to develop them into change-making projects together and have fun doing so.

Moving on to company decision-making, the nature of Enspiral as a network of relations between people who want to create positive change affects how and on what grounds decisions are made. 'Enspiralites' well-being, which is intimately tied to the well-

\footnotetext{
${ }^{112}$ Will Lau, "The Bucky Box Startup Story," Enspiral, http://blog.enspiral.com/2011/03/04/the-buckybox-startup-storyl (accessed May 11, 2011).
} 
being effects Enspiral work has on client organisations, communities and the environment, is primary. The thinking seemed to be that if 'Enspiralites' flourish, other stakeholders will be better off, too. The company's activities overall need to generate a positive return. Moreover, the greater the return is, the more good the company can do, as profits can be re-invested in the business and in worthy causes. Still, one year into its operations, the company did not yet have economic targets.

Many decisions that in conventional companies would be made by company management are made by 'Enspiralites' themselves. Individuals and groups have much room to initiate and do the types of projects they feel like doing and decide their preferred methodology. According to Josh and Sam, trial and error has been the dominant method of developing Enspiral up until now.

Informality also characterises company-wide decision-making. When there is a question about where to go as a company and how - of defining 'what makes us tick', as Josh put it - the company wiki is used to gauge the views and opinions of 'Enspiralites'. The company blog allows clients and the wider community to tell what they think. In addition to the digital space, arguments and emotions are expressed in conversations. The first physical meeting of all 'Enspiralites', a company hui, was being planned when I visited Enspiral. Josh and Sam called their approach to decision-making 'wisdom of the crowds'. The approach is inherently collaborative. The leadership's well-being consists in facilitating well-being for every member of the organisation, one individual or group's well-being depends on and adds to others' well-being, and the most important well-being effects are the shared ones.

However, it became clear in our discussion that this informal, intense and resourceconsuming approach to decision-making is not suited to all Enspiral decisions. In small dayto-day operational decisions, stakeholders do not need to be troubled with participating in decision-making, and the leadership can legitimately call the shots. At the other end of the spectrum, in some important and big decisions, a consensus might not emerge from the colloquial process. We talked about projects where the 'goodness' of a client organisation's 
objectives or the value of a project on which an Enspiral team wishes to work is debatable, and people simply may not agree on whether Enspiral should get involved or not.

Such controversial decisions, as well as economic decisions, are made by 'Enspiralites' according to a hierarchy of employee roles within the company. Members of Enspiral, who are called to membership by fellow Members, have the right to vote, while Contributors and Contractors have the right to inform decisions. An interesting feature of this model is that it, too, is more democratic than traditional management-driven decisionmaking. Not only the leadership but also trusted fellow employees decide the weights different 'Enspiralites' have in deciding on questions that cannot be decided colloquially. Furthermore, even if Contributors and Contractors do not have a say in the final decisions, their opinions are still highly influential for Members' decision-making.

In conclusion, Enspiral undoubtedly cherishes a humanistic conception of the good. Still, knowing what it requires is not always easy. The above example of controversial projects illustrates this. So does finding a balance between projects where 'Enspiralites' themselves see value and projects that accord with customers' wishes but do not necessarily advance a social or an environmental cause. I got the impression that the main challenge for Enspiral as a fast growing company with increasingly many interpretations of the 'good' may be to develop a sufficiently shared understanding of it. Josh and Sam showed awareness of this and considered two features of their organisation as particularly useful for determining the Enspiral 'good'. First, the leadership attempts to show by their own example what is good and to promote people and projects that advance particularly valuable or worthy causes. Second, openness characterises the organisation's search for good pursuits. The overriding company dynamic requires individuals and groups within Enspiral to make a case for their beliefs and aspirations.

\subsection{The 42collective}


The 42collective's objective, according to one leader in the organisation, Ben Gleisner, is to facilitate ethical consumption choices for consumers and to make ethical business practices more attractive for companies. Currently, the 42collective aspires towards this objective, through its main project Conscious Consumers, by certifying cafes for ethical, socially and environmentally responsible practices. However, there is no reason why interesting projects could not be found in other industries in the future. As Wellington has a lively café scene and as cafes already have a reputation as agents of change, they were a natural business with which to start for the organisation. As a non-profit, the 42collective does not have economic objectives and is not subject to economic constraints, other than the need to finance its activities. Success for the 42collective is seeing New Zealand consumers' and companies' behaviours become more ethical.

The 42collective's operations enhance the well-being of New Zealand consumers, New Zealand companies, New Zealand communities, the environment and the organisation's leaders and volunteers in ways suggested by my conception of the good. Given its pure wellbeing orientation, it is not surprising that the organisation's decision-making is additionally conducted according to the principles I proposed in part two.

The 42collective aims to "make Wellington a place where it is easy for people to live environmentally and socially responsible lifestyles". ${ }^{113}$ Thus, the organisation has come about and exists because it believes it can make a difference to Wellingtonians' (and New Zealanders') well-being by allowing them to consume in a sustainable way. Ethical consumption choices, however, are possible only if there are businesses that offer them. Consequently, Wellington and New Zealand cafes are an equally important stakeholder group to the 42collective. It can make the cafes (and in the future, other companies) better off by showing them and discussing with them what responsible business practices require, and by allowing them to signal that they follow such practices. Furthermore, the environment

\footnotetext{
113 The 42collective, "The 42collective," http://www.42collective.org.nz/ (accessed April 25, 2011).
} 
benefits from companies adopting more responsible practices with regard to, say, sourcing raw materials, waste management or energy efficiency.

Beyond individual consumers, companies and the environment, the 42collective's work has positive well-being effects in the communities in which the consumption and production activities it targets take place. For example, if cafes buy only fair trade coffee, coffee-producing communities in the developing world become better off. Closer to home, Conscious Consumers volunteers and cafes recently organised a community event called 'Carrotmob' in Wellington. Any interested members of the 42collective, of which there are 600 , were invited to participate in arranging the event, spreading information about it and participating with friends and family. ${ }^{114}$ The idea was that during one day, all the money spent by consumers at one of Conscious Consumers' member cafes, plus what the cafe promised to spend additionally, was invested in improving the café's energy efficiency. ${ }^{115}$ In addition to raising money to a worthy cause, the Carrotmob was arranged to spread information about Conscious Consumers and ethical consumption practices in general, as well as to bring together Wellingtonians around one of their favourite pastimes, enjoying a good cup of coffee.

Finally, the 42collective presumably brings well-being to its leaders and volunteers, too - otherwise it is hard to see why they would spend their free time, energy and expertise with the organisation. Providing people with not only enjoyable but meaningful spare time activities in an inspirational community is a powerful well-being outcome. Ben described working with the 42collective and Conscious Consumers as a highly valuable complement to his paid job as a civil servant. Furthermore, as most Conscious Consumers volunteers are young people, they gain valuable experiences of organisational life and new skills for their future careers.

\footnotetext{
${ }^{114}$ The 42collective, "Get involved," http://www.42collective.org.nz/get involved.html (accessed April $25,2011)$.

${ }^{115} 42$ collective, "Carrotmob at Memphis Belle," http://www.consciousconsumers.org.nz/aboutus/events/carrotmob-at-memphis-belle (accessed April 25, 2011).
} 
Moving on to decision-making, all stakeholder groups' interests are balanced in developing the 42collective and its activities. Decisions are made with consumers' interests in mind, as the purpose of the organisation is to advance ethical consumption opportunities. At the same time, the demands on participating businesses need to be reasonable, and the membership fees Conscious Consumers charges need to represent good value for money. Leaders and volunteers' ideas and preferences, in turn, determine where the 42collective gets involved and how. Decisions are made based on the well-being potential of an activity. For example, the industries where the 42collective operates are chosen based on how feasible it is to improve the information flow from companies to consumers in the industry, and how much environmental and social benefit can be expected from changed behaviours. In the 42collective, an 8-member committee elected by the organisation's members has responsibility for making decisions. Still, transparency that allows any committee proposal to be challenged by every member of the 42 collective and openness for this to happen are considered critical, according to Ben. Additionally, members are always free to make proposals of their own. Ben described the organisation's decision-making as following a participatory, communitarian model where all stakeholders need to feel that they have ownership of the 42collective's strategy. Decision-making is informal; the organisation evolves based on the collective wisdom that emerges from arguments and emotions expressed in meetings, events and the digital space. The organisation's approach towards its stakeholders is highly collaborative. A good project is by definition one that increases all involved parties' well-being.

In conclusion, a humanistic conception of the good underlies the 42collective's ideology and practice. Still, getting people to commit to even as worthy a cause as Conscious Consumers is not without challenges. People have many demands and opportunities in their spare time, and Ben mentioned that reliability of volunteers to do what has been agreed is always a challenge for non-profit organisations. The way to mitigate this difficulty, according to Ben, is to continue to develop the 42collective's activities and 
community so that they would be experienced as meaningful and enjoyable as possible by the organisation's volunteers.

\subsection{Common practices with respect to stakeholder well-being}

The case studies show that there are companies for whom it is both possible and practical to cherish a humanistic conception of the good. Furthermore, the case studies show that companies may have good reasons for caring about stakeholder well-being and implementing the types of decision-making principles I have suggested, whether for wellbeing's sake, for profitability's sake or both. As I only studied four companies, I can generalise little beyond these overall findings. Every company, after all, has its own, unique and specific interpretation of the good which depends on its culture, people, other resources, product or service, and the competitive forces in its industry. Nevertheless, it seems that despite their differences, Wheelworks, Enspiral and the 42collective share certain common practices with respect to how they think about and aim for stakeholder well-being. I describe these briefly, as they may be indicative of how companies with a humanistic conception of the good generally choose and act.

\subsubsection{Drivers of company development}

Two questions seem to drive humanistic companies' development: how can we help our customers' lives go better for them, and what does our staff desire to do?

Wheelworks, Enspiral and the 42collective exist, firstly, in order to meet some unfulfilled customer need or want. The 42collective offers an altogether new service. There are no other players that provide Wellington or New Zealand consumers with information about the ethical implications of going to their local café. Wheelworks and Enspiral, in turn, improve on existing products and services. Bike wheels are available in Wellington, but 
Tristan tailors them locally to individual cyclists' preferences and packages the product with knowledgeable service. Similarly, many companies offer software services in Wellington, but none allows their developers as much entrepreneurial and creative freedom or target environmentally and socially valuable projects as ambitiously as Enspiral.

Nevertheless, not any unfulfilled customer need or want suffices for these companies. For Wheelworks, Enspiral and the 42collective, the need or want has to be such that meeting it makes a genuine difference to their customers' well-being. As we have seen, these companies' products and services improve their customers' health, make their lives more enjoyable or allow them to realise projects that sustain or develop a community. It is also possible that a company's product or service makes its customers' lives easier and thereby allows them to spend a greater part of their time and energy on things that really matter for their well-being; this can be a desirable outcome, too.

As customers' well-being is so central to Wheelworks', Enspiral's and the 42collective's existence, the first question they ask themselves when faced with decisions about how to develop their company is which of the solutions proposed would make their customers' lives go better for them. The second question is which of the solutions their staff would desire to work with.

Wheelworks, Enspiral and the 42collective exist, secondly, in order to allow people first a core group of leaders and gradually more likeminded employees or volunteers - to put into action their ambitions and ideas, to use their skills and personal qualities and to enjoy their jobs. I got the impression that for Tristan, Wheelworks was very much about realising his vision, based on his skills and personal qualities, of what a good bike shop should be like. Despite their greater size, it seemed that Enspiral and the 42collective were similarly about people realising their own, though of course mutually compatible and even complementary, thoughts about what a good IT service company or a consumer organisation should be like and what their unique role can be in bringing it about. It appeared to be essential to these companies that their employees and managers have much room to pursue projects they burn for, in ways they want. 
What happens if customers' well-being and staff's desires would recommend a different solution in a decision? For Wheelworks, Enspiral and the 42collective, such a situation is unlikely, as the two well-being outcomes are seen as interconnected. The companies believe that no matter what their staff's individual work-related preferences are, their managers and employees find their work meaningful and enjoyable only if what they do also enhances customers' well-being. Similarly, they believe that customers' well-being cannot be enhanced unless their products and services are passionately created. Thus, any good solution to any decision of company development is such that it makes both of their key stakeholder groups better off.

\subsubsection{Approach to staff}

Humanistic companies seem to have great respect for their staff, to engage them in all significant decisions and to be attentive to their needs.

Making staff's desires about what they want to do central to decisions of company development is just one, though maybe the most important, aspect of how their managers' and employees' well-being features in Wheelworks, Enspiral and the 42collective decisionmaking. An attitude of respect for staff permeates all company activity. This is clear in two practices, in addition to the one already discussed: the companies engage their staff in all significant decisions and are attentive to their needs.

First, Enspiral's and the 42collective's owners and leaders - it will not be relevant to include Wheelworks here as it is a one-man business - see their role in decision-making to be to set the agenda and to facilitate good decisions instead of to necessarily make all company decisions. Employees are involved in decision-making through every stage of the process, from suggesting solutions to taking responsibility for implementing them. They participate in the multiple fora in which decisions are prepared, from the digital space to formal decision-making organs. Not only are their arguments heard, but it is expected and 
encouraged that employees express how they feel about different solutions and why. In all internal company interactions, the owners and leaders have their sensors out for what the employee spirits are like. They try to understand the causes of any dissatisfaction and cherish and join in excitement. Many company decisions can be better characterised as 'emerging from' such interactions than as 'being made'.

Second, Wheelworks, Enspiral and the 42collective go to considerable lengths to attend to their staff's needs. They do expect engagement and results from their staff - or, in the case of Wheelworks, Tristan expects much of himself - but provide a large degree of freedom and flexibility in return. The companies understand that people differ in how, where and when they work best and, perhaps most importantly, that people have important things in their lives other than work or their organisation's activity. There is particular appreciation for the demands and opportunities of different family situations, so that it is considered natural that the degree to which people are able and willing to dedicate themselves to work will vary from one time period to another. The companies also take many practical steps to enhance their staff's well-being at work, such as providing pleasant work spaces and encouraging healthy lifestyles.

\subsubsection{Approach to communities and the environment}

Humanistic companies seem to consider supporting the well-being of their local and global communities and having responsible environmental practices to be natural parts of being a business and doing business.

Enspiral's and the 42collective's services advance environmental and social causes in their local communities. Instead of arising from what individual consumers want, many of Enspiral's software projects and the 42collective's Conscious Consumers project are based on identifying needs in the community that the government, traditional companies or the voluntary sector do not yet cater for. This can only happen if the companies' staff takes part 
in community life. Often, ideas for projects come from understanding some global or local community trend, and stepping in to address it. Examples of such trends are the greater willingness of communities to work on local environmental concerns, the potential of online communication to bring people together around specific causes in their community, and the problem of increased loneliness of the elderly and other vulnerable community members. Although Wheelworks' product is directed more at meeting private preferences, the idea of hand-crafted, high quality bike wheels, Tristan's service concept and Wheelworks' evolution are tied to the cycling community's needs and to understanding these needs as an insider.

In addition to creating services and products for communities, Wheelworks, Enspiral and the 42collective let their staff's passions and expertise stimulate and guide further kinds of community involvement. Tristan's role as the sponsor, manager and mechanic of Wheelworks Racing springs from his interest in cycling and the skills Wheelworks has equipped him with. Enspiral staff arranges their work so that they can pursue extra-work aspirations that have personal well-being effects but that also develop and strengthen various communities. The company's founder dedicates much time to a youth leadership network, another key 'Enspiralite' takes time off to play music and Sam uses one day a week on environmental education. ${ }^{116}$ The 42 collective's Carrotmob community event at a Wellington café came about because it seemed like a natural setting for the organisation's members to meet people and spread the message about ethical consumption. In all aspects of their operations, these companies view themselves and their staff as community members with all the opportunities and responsibilities that that view entails.

One particularly important responsibility - and one with regard to which the companies take on both a local and a global perspective - is environmental citizenship. It seemed to be self-evident to Wheelworks, Enspiral and the 42collective that they should minimise the harm their business and activities cause on the natural environment. Having no physical facilities, the 42collective's ecological footprint is probably the smallest of the three,

\footnotetext{
${ }^{116}$ Sam Rye, "New working paradigm = new possibilities," Enspiral, http://blog.enspiral.com/2011/04/28/new-working-paradigm-new-possibilities/ (accessed May 11, 2011).
} 
but Enspiral and Wheelworks are also more environmentally friendly than most companies. As 'Enspiralites' work only partly in the company office, the demands on office space are more modest and the need to travel is less. Furthermore, all equipment is acquired by groups of employees at their own expense which reduces unnecessary purchases. Tristan was otherwise pleased with the environmental performance of his workshop, but hoped he could reduce the packaging waste that comes with the bike parts he uses for his wheels.

\subsubsection{Culture}

Humanistic companies seem to acknowledge that creating and sustaining a focus on stakeholder well-being is tricky, and place particular importance on good leadership, openness and trust in solving challenges that bear upon stakeholder well-being.

The leaders of Wheelworks, Enspiral and the 42collective I met were modest. Their primary objective is the advancement of people's well-being instead of profit maximisation, and their decision-making is accordingly people-centric, not profit-centric. Still, they do not think it is easy to know how to be a humanistic company or organisation. As we saw earlier, each of the companies identified challenges with their orientation: Wheelworks with the wellbeing value of its product and the balance of well-being ambitions with economic constraints, Enspiral with the shared definition of the 'good' and the 42collective with the commitment of its people. In our conversations, I got the impression that Wheelworks, Enspiral and the 42collective consider three aspects of culture to be critical in succeeding as a well-being oriented company, all of which would be recommended by my ethical theory, too.

First, leaders need to be visionary and involved. In part one, I argued that even in our private lives, it is difficult to determine what choices and actions would best contribute to human flourishing in any given situation. Sometimes, the different ends of a characteristic good human life conflict, or there are conflicts between the interests of different people. Questions about well-being are likely to be even trickier in a company context where we 
have to succeed with a purpose - producing and selling a good or a service - with people whose well-being is only partly overlapping with ours. In such a situation, leaders are needed to create a shared vision, exemplifying it and continuously helping the organisation determine what kinds of things are conducive to realising the vision and what are not.

Second, the company culture needs to be open. I suggested in part one that a good human life makes room for our unique capabilities, likes and life projects. We are challenged to figure out individually and with the people who are close to us what, say, good family life, enjoyment or meaningful work is for us, using our reasoning abilities and emotional sensitivities as aids. When we join a community like a company, and try to realise together those aspects of our well-being that have to do with our roles as company stakeholders, we are likely to make little progress unless we are open about what does and does not make our lives go well for us.

Third, there needs to be trust between stakeholders. This is required for openness but also for stakeholders to succeed in their role as informants, decision-makers and actors who aim for well-being. If the best solutions to problems of well-being are to be found, the relevant stakeholders need to be trusted to be the authorities on their own well-being. Moreover, if stakeholders are to learn how to choose and act so that their own and other stakeholders' well-being is enhanced, they need to be trusted with autonomy to find unconventional solutions to problems, including acceptance of the fact that they may sometimes make mistakes. Furthermore, if stakeholders are to take their well-being roles seriously, they need to be held responsible for their choices and actions and also to take corrective action if they have made mistakes.

Without doubt, leaders play a key role in companies' cultural development. They can support and exemplify behaviours, practices and activities that show openness and trust in action. Nevertheless, the most important way of strengthening openness and trust is probably simply to encourage stakeholders to be as much their own persons as possible and to learn to know each other better. This can happen through working together on something that both parties care about. When a fellow employee or a customer becomes a friend, or at 
least a person with whom we have pleasant encounters, it is much more likely that we open up and learn to trust each other.

\subsection{Emerging thoughts about the status of stakeholder well-being}

I close part three with some emerging thoughts about the status of stakeholder wellbeing in New Zealand companies, and maybe Western businesses in general. Even more so than the above similarities I observed in how Wheelworks, Enspiral and the 42collective approach stakeholder well-being, these thoughts are for further empirical study to confirm (or not).

The first emerging thought has to do with the relevance of ethical frameworks to the business context. Although company managers are often unfamiliar with the language and methods of philosophical ethics, they seem to be able to grasp quickly how ethical theory can be applied to their setting and find it a relevant and interesting complement to how ethical issues are handled in business and management literature. Well-justified argumentation is what managers expect regarding other business issues, and they therefore welcome the rigour with which ethical theory treats value judgements (which often may be greater than the rigour with which business and management literature treats value judgements). If our goal is for ethical issues to be incorporated into company decisionmaking in a serious way, philosophical ethics, appropriately developed and applied, may be our best bet.

The second emerging thought has to do with the significance of company size and ownership structure for how feasible company managers view a conception of the good as stakeholder well-being to be. The smaller the company and the more integrated the company ownership and management, the tighter is the relationship between the leadership and other stakeholders and the shorter is the distance between decision-making and operations. In such a setting, it seems to be natural for company managers to care about their stakeholders' well-being and easy for them to see how they can do so. 
It is as if larger companies have a life of their own independent of the lives of their managers, which somehow justifies a divergence between what managers decide and what the human good would require the company to do. Additionally, if managers act as owners' agents, and if owners have primarily economic interests in the company, managers may consider that they do not have other options than to pursue profit maximisation. However, I argued in part two that owners give managers plenty of freedom in their economic decisionmaking; they may also do so in other questions, especially if the long-run profitability potential of the company is not undermined. It at least seems to me that managers who are convinced of the value of an orientation towards stakeholder well-being have a responsibility to make their case to the owners.

The third emerging thought concerns the significance of time perspective for how important company managers consider stakeholder well-being to be. Especially in companies with a profit maximisation focus, managers seem to be much more sympathetic to actions and choices that would advance stakeholder well-being if they are asked about their long-term strategy than if they consider their short-term priorities.

It is as if companies could not afford to pay regard to stakeholder well-being in the short run. If this is correct, the attitude can probably be explained by the greater convergence of economic and well-being considerations in the long run than in the short run discussed in part two. Still, the long run is nothing but a series of short runs, and hiding behind the argument that we will start taking stakeholder well-being seriously next year, but not just yet, is no more acceptable than avoiding responsibility for the human good because "I just work here" or "my owners will not accept other objectives than profit maximisation anyway" (the above arguments).

\section{Conclusion}

In my thesis, I have developed one ethical theory that could guide the quest for a new business paradigm in the Western world in the early 2010s. My theory of human flourishing 
recommends that companies put stakeholder well-being at the centre of their operations and re-configure company decision-making accordingly. Some companies already do this, with success, as I have discussed.

The most important question humanistic companies ask themselves is: how can we facilitate the achievement of characteristic good human ends for our customers through our products and services and for our staff through the work we do? Humanistic companies acknowledge that many of customers' and staff's projects and enjoyments are experienced as most meaningful when shared, but that their origin is in individuals' unique capabilities, likes and life projects. Although exciting outcomes can be achieved when products, services and work are approached from a well-being perspective, humanistic companies also recognise that they do not operate in a vacuum. They make room for staff's commitment to their families and for staff's and customers' involvement in local and global communities. Finally, given the vulnerability of our natural environment, humanistic companies consider responsible environmental practices a natural part of doing business.

A focus on stakeholder well-being invites many changes to company decisionmaking, compared to the situation in which profit maximisation is considered to be the proper objective of business. Humanistic companies give priority to the interests of those stakeholders who are most affected by any given decision. They base decisions not only on economic considerations but also on assessment of how various solutions impact stakeholders' well-being. Perhaps most importantly, humanistic companies engage stakeholders in decision-making that affects their well-being and make more room for informal influences in the decision-making process. Finally, decision-makers in humanistic companies are less concerned about how stakeholders can help the company win over competition and focus more on collaborating with stakeholders on their well-being. Decisionmaking is more complex than for profit-maximising companies, but weighing the reasons and emotions that accompany the various solutions should help humanistic companies in comparing the goodness of the alternatives. 
My case studies with four Wellington-based companies, Interislander, Wheelworks, Enspiral and the 42collective, provide evidence that such an operational model is possible, practical and beneficial, whether assessed from a stakeholder well-being or an economic perspective. Still, I have only studied four companies, three of which were selected due to their humanistic profile. I acknowledge the possibility that if a profit maximising company chooses to focus on stakeholder well-being, some of its stakeholder groups may need to give up money, power and the possibility to be unengaged.

Starting from money, there is evidence that companies that choose an orientation towards stakeholder well-being tend to be rewarded for this economically, at least in the long run, as was discussed in part two and in connection with the case study of Interislander. If this is the case, there does not need to be a reduction in any of the stakeholder groups' economic benefits (though companies may choose to re-distribute their economic benefits differently, as I also pointed out in part two). However, a humanistic company may, in any given decision, choose to follow a course of action that is more expensive, or brings in less revenue, than a course of action a profit-maximising company would choose.

For example, if a humanistic company becomes a more flexible employer, makes quality improvements for its customers or puts in place more stringent environmental standards, its costs per unit of output go up. The company then has three options. First, it can try to cut costs in areas that would be neutral for stakeholder well-being, such as unnecessary administration, so as to keep its total costs unchanged. Second, the company can reduce employee salaries or supplier payments so as to keep its total costs unchanged, or charge a higher price for its product or service so as to increase its revenues. If it does this, its employees, suppliers or customers end up in a worse economic position. Third, the company can do nothing and merely absorb the higher costs in its profit margin, which means that it will pay less profit to its owners. Often, the company is likely to prefer the third option, because its earlier profit-maximising orientation favoured the owners' interests, as explained in part two. 
If the economic benefits of some of the company's stakeholders are reduced as a result of such well-being enhancing decisions, they can choose to end their dealings with the company. In particular, two types of stakeholders are in the risk zone for leaving the humanistic company: detached owners, who see the company as a source for quick profits, and customers, who are interested in the cheapest possible product or service, irrespective of its other effects. If any loss of stakeholders occurs, the company may become smaller in size, though this of course depends on how many new stakeholders its orientation around stakeholder well-being attracts. Based on my own and others' evidence, humanistic companies tend to grow rather than shrink.

Moving on to power, this is an established good on par with money. Some stakeholder groups, most notably managers and owners, are used to having an authoritative and dominant influence on a profit-maximising company's choices and actions, as they are most often best placed to assess the profitability of various options. A humanistic company, however, can achieve results with its objective of advancing stakeholder well-being only if the people whose well-being is at stake in any given situation are engaged in decisionmaking on par with managers and owners. All stakeholders have a say in what the company does, and how.

Finally, in a profit-maximising firm, it may be possible to do one's job conscientiously and according to requirements, but think little about how the job could be done better, or how it could be made more fun or meaningful. This is because for many employees, profit maximisation is a distant objective, and incentives to see what difference one's own job can make to the achievement of the overall objective are limited. In a humanistic company, it seems like the minimum requirement for employees is to communicate with other stakeholders about what their good consists in and work so as to achieve it. Staff members who refuse to become thus engaged are unlikely to survive in the company, for the other stakeholders, including those who make decisions on hiring and firing, do not know what they can do for the company and what the company can do for them. 
We may ask how serious is the possible loss of stakeholders, who primarily pursue generous quick-win profits, a bargain, power, or a job towards which they feel indifferent, for a company that aims for stakeholder well-being. The most important stakeholders for a humanistic company are those who actively contribute to its ambitions regarding stakeholder well-being and appreciate the outcomes of such ambitions. According to my theory of human flourishing, every person has the possibility to be such a stakeholder, as we all share the same characteristic good human ends and can aspire towards them, from our different starting points. One way to look at my thesis is as an invitation for business actors to consider how, if this is the case, their company or work place could fulfil its potential as an agent of well-being. 


\section{Bibliography}

Annas, Julia. The Morality of Happiness. New York: Oxford University Press, 1993.

Barton, Dominick. "Capitalism for the Long Term." Harvard Business Review, March 2011, 84-91.

Berman, Shawn L., Andrew C. Wicks, Suresh Kotha, and Thomas M. Jones. "Does Stakeholder Orientation Matter? Relationship between Stakeholder Management Models and Firm Financial Performance." The Academy of Management Journal 42, no. 5 (1999): 488-506.

Boatright, John B. "What's Wrong - and What's Right - with Stakeholder Management." In Ethical Theory and Business, $8^{\text {th }}$ ed., edited by Tom L. Beauchamp, Norman Bowie, and Denis Arnold, 69-80. New Jersey: Pearson Prentice Hall, 2009.

Bradley, Chris, Martin Hirt, and Sven Smit. "Have you tested your strategy lately?" McKinsey Quarterly, January 2011.

https://www.mckinseyquarterly.com/Strategy/Have you tested your strategy lately 2711 (accessed February 24, 2011).

Brooks, David. "Social animal: how the new sciences of human nature can help make sense of a life." The New Yorker, January 17, 2011.

Csikszentmihalyi, Mihaly. "Mihaly Csikszentmihalyi on Flow." TED.

http://www.ted.com/talks/mihaly csikszentmihalyi on flow.html (accessed January 7, 2011).

Cohen, Gerald A. "Equality of What? On Welfare, Goods and Capabilities." In The Quality of Life, edited by Martha C. Nussbaum, and Amartya Sen, 9-29. New York: Oxford University Press, 1993.

Conner, Kathleen R. (1991). "A Historical Comparison of Resource-Based Theory and Five Schools of Thought within Industrial Organization Economics: Do We Have a New Theory of the Firm?" Journal of Management 17, no. 1 (1991): 121-154.

Coyne, Kevin. P., and Somu Subramaniam "Bringing Discipline to Strategy." McKinsey Quarterly, no. 4, 1996, 61-70.

Elms, Heather, Stephen Brammer, Jared D. Harris, and Robert A. Phillips. "New Directions in Strategic Management and Business Ethics." Business Ethics Quarterly 20, no. 3 (2010): 401-426. 
Forgeard, Marie J. C., Eranda Jayawickreme, Margaret L. Kern, and Martin E. P. Seligman "Doing the Right Thing. Measuring Wellbeing for Public Policy." International Journal of Wellbeing 1, no. 1 (2011): 79-106.

http://www.internationaljournalofwellbeing.org/index.php/ijow/article/view/4 (accessed March 16, 2011).

Foot, Philippa. Natural Goodness. New York: Oxford University Press, 2001.

Freeman, R. Edward. "Managing for Stakeholders." In Ethical Theory and Business, $8^{\text {th }}$ ed., edited by Tom L. Beauchamp, Norman Bowie, and Denis Arnold, 56-68. New Jersey: Pearson Prentice Hall, 2009.

Friedman, Milton. "The Social Responsibility of Businesses Is to Increase its Profits." The New York Times Magazine, Sept 13, 1970. Reprinted in Ethical Theory and Business, $8^{\text {th }}$ ed., edited by Tom L. Beauchamp, Norman Bowie, and Denis Arnold, 51-55. New Jersey: Pearson Prentice Hall, 2009.

Harrison, Jeffrey S., Douglas A. Boss, and Robert A. Phillips. "Managing for Stakeholders, Stakeholder Utility Functions and Competitive Advantage." Strategic Management Journal 31, no.1 (2010): 58-74.

Hasnas, John. "The Normative Theories of Business Ethics: A Guide for the Perplexed." Business Ethics Quarterly 8, no. 1 (1998): 19-42.

Hine, James, and Lutz Preuss. "Society is out there, organisation is in here: On the perceptions of corporate social responsibility held by different managerial groups." Journal of Business Ethics 88, no. 2 (2009): 381-393.

Hursthouse, Rosalind. On Virtue Ethics. New York: Oxford University Press, 1999.

Jarzabkowksi, Paula, Julia Balogun, and David Seidl. "Strategizing: The challenges of a practice perspective." Human Relations 60, no. 1 (2007): 5-27.

Johnson, Gerry, Leif Melin, and Richard Whittington. "Micro Strategy and Strategizing: Towards an Activity-Based View." Journal of Management Studies 40, no. 1 (2003): 3-22.

Jones, Thomas M., Will Felps, and Gregory A. Bigley. "Ethical Theory and Stakeholderrelated Decisions: The Role of Stakeholder Culture." Academy of Management Review 32, no. 1 (2007): 137-155.

Kahnemann, Daniel. "The Riddle of Experience vs. Memory." TED. http://www.ted.com/talks/daniel kahneman the riddle of experience vs memory.html (accessed January 7, 2011). 
Keller, Simon. "Welfare as Success." Nous 43, no. 4 (2009): 656-683.

Kramer, Mark. R., and Michael E. Porter. "Creating Shared Value." Harvard Business Review, January-February 2011, 63-77.

Lau Will. "The Bucky Box Startup Story." Enspiral. http://blog.enspiral.com/2011/03/04/thebucky-box-startup-story/ (accessed May 11, 2011).

Lenman, James. "Moral Naturalism." Stanford Encyclopedia of Philosophy. http://plato.stanford.edu/entries/naturalism-moral/ (accessed December 14, 2010).

Luukkonen, Risto. "Notes on Scheler, Frankl, Graber and Solasaari." (Quote-based notes borrowed from the author's father.)

Macy, Jonathan R. "Fiduciary duties as residual claims: obligations to non-shareholder constituencies from a theory of the firm perspective." Cornell Law Review 84 (1999): 12661281.

Marcoux, Alexei. "Business Ethics." Stanford Encyclopedia of Philosophy. http://plato.stanford.edu/entries/ethics-business/ (accessed January 28, 2011).

Marens, Richard, and Andrew Wicks. "Getting Real: Stakeholder Theory, Managerial Practice, and the General Irrelevance of Fiduciary Duties Owed to Shareholders." Business Ethics Quarterly 9, no. 2 (1999): 273-293.

Nussbaum, Martha C. "Non-Relative Virtues: An Aristotelian Approach." In The Quality of Life, edited by Martha C. Nussbaum, and Amartya Sen, 242-269. New York: Oxford University Press, 1993.

Offer, Avner. "Economic Welfare Measurements and Human Well-Being." University of Oxford: Discussion Papers in Economic and Social History 34 (2000): 1-35.

Porter, Michael E. "The Five Competitive Forces That Shape Strategy." Harvard Business Review, January 2008, 79-93.

Porter, Michael E. "What is Strategy?" Harvard Business Review, November-December 1996, 61-78.

Putnam, Hilary. "Objectivity and the Science-Ethics Distinction." In The Quality of Life, edited by Martha C. Nussbaum, and Amartya Sen, 143-164. New York: Oxford University Press, 1993. 
Roadcycling New Zealand. "Team Overview: Wheelworks Racing."

http://www.roadcycling.co.nz/TeamTalk/team-overview-wheelworks-racing.html (accessed April 12, 2011).

Rye, Sam. "New working paradigm = new possibilities." Enspiral.

http://blog.enspiral.com/2011/04/28/new-working-paradigm-new-possibilities/ (accessed May 11, 2011).

Sayre-McCord, Geoff. "Metaethics." Stanford Encyclopaedia of Philosophy. http://plato.stanford.edu/entries/metaethics/ (accessed November 8, 2010).

Scanlon, Thomas. "Value, Desire, and Quality of Life." In The Quality of Life, edited by Martha C. Nussbaum, and Amartya Sen, 185-200. New York: Oxford University Press, 1993.

Sen, Amartya. "Capability and Well-being." In The Quality of Life, edited by Martha C. Nussbaum, and Amartya Sen, 30-53. New York: Oxford University Press, 1993.

Sinnott-Amstrong, Walter. "Consequentialism." Stanford Encyclopaedia of Philosophy. http://plato.stanford.edu/entries/skepticism-moral// (accessed Nov 23, 2010).

Sinnott-Amstrong, Walter. "Moral Skepticism." Stanford Encyclopaedia of Philosophy. http://plato.stanford.edu/entries/skepticism-moral/ (accessed November 7, 2010).

Sisodia, Rajendra S., David B. Wolfe, and Jagdish N. Sheth. Firms of Endearment. New Jersey: Wharton School Publishing, 2007.

Social Enterprise Coalition. "About social enterprise." http://www.socialenterprise.org.uk/pages/about-social-enterprise.html (accessed April 15, 2011).

Stark, Andrew. "What's the Matter with Business Ethics." Harvard Business Review, MayJune 1993, 38-48.

Stieb, James A. "Assessing Freeman's Stakeholder Theory." Journal of Business Ethics 87 (2009): 401-414.

Sumner, Leonard W. Welfare, Happiness, and Ethics. New York: Oxford University Press, 1996. 
The 42collective. "Carrotmob at Memphis Belle."

http://www.consciousconsumers.org.nz/about-us/events/carrotmob-at-memphis-belle (accessed April 25, 2011).

The 42collective. "Get involved." http://www.42collective.org.nz/get involved.html (accessed April 25, 2011).

The 42collective. "The 42collective." http://www.42collective.org.nz/ (accessed April 25, 2011).

Tiberius, Valerie. "Well-Being: Psychological Research for Philosophers." Philosophy Compass 1, no. 5 (2006): 493-505.

Wilkinson, Richard, and Kate Pickett. The Spirit Level. London: Penguin Books, 2009. 